\title{
CSR initiatives, organizational performance and the mediating role of integrating CSR into management control systems: Testing an inclusive model within SMEs in an emerging economy
}

\author{
Walid Cheffi $^{1}$ (D) . Ahmed Abdel-Maksoud ${ }^{1} \cdot$ Muhammad Omer Farooq $^{1}$
}

Accepted: 20 May 2021 / Published online: 10 June 2021

(C) The Author(s), under exclusive licence to Springer-Verlag GmbH Germany, part of Springer Nature 2021

\begin{abstract}
This paper addresses a current gap in the literature by investigating the mediating role that integrating corporate social responsibility (CSR) into the management control systems (MCS) of small and medium-sized enterprises (SMEs) can play in the relationship between CSR initiatives and organizational performance. We propose, and empirically validate, an inclusive model to examine these relationships. The study then extends further by embedding two constituents of CSR integration into MCS: namely, management control technology and involvement of management accountants in CSR management. Our study is distinguished by validating, as a contribution, a single construct for each of these two constituents. Data were collected from 117 SMEs in an emerging economy, Abu Dhabi-UAE. PLS structural equation modeling was used in the data analysis. We find that CSR initiatives in SMEs influence organizational performance both directly and indirectly through MCS. Interestingly, the results show that only the involvement of management accountants in CSR management mediates the relationship between CSR initiatives and SME performance. This indicates that the role of human intervention prevails over technology intermediation in conveying the positive effect of CSR initiatives on organizational performance. Overall, the findings help to understand how MCS is an important driving mechanism whereby SMEs may derive performance outcomes from deploying CSR initiatives. The study concludes with implications for future research and policy-makers.
\end{abstract}

Keywords Corporate social responsibility · SMEs · Management control systems · Organizational performance $\cdot$ Mediation effect $\cdot$ Emerging economy

Walid Cheffi

walid.cheffi@zu.ac.ae

Extended author information available on the last page of the article 


\section{Introduction}

The positive contribution of small and medium-sized enterprises (SMEs) to gross domestic product is beyond doubt, but their cumulative negative contributions to the environment and the welfare of society are of concern to policy-makers in all nations. Yet, compared with large firms (Lee et al., 2016; Niehm et al., 2008), little is known about the extent of corporate social responsibility (CSR) implementation in SMEs. Many researchers highlight the seriousness of the knowledge gap in the business literature pertaining to the effects of CSR in SMEs (Casadei \& Amadei, 2010; Martinez-Conesa et al., 2017; Morsing \& Perrini, 2009).

The extant literature on CSR has converged to conclude that SMEs have become aware that their social behavior is critically evaluated by stakeholders. An increasing belief among SME owners and managers is that CSR initiatives ${ }^{1}$ can provide organizational legitimacy and stability (Du \& Vieira, 2012; Tomsic et al., 2015). However, this growing organizational awareness is accompanied neither by formal planning and control processes nor by regular actions (Lee et al., 2016). Commentators note that SMEs' engagement in CSR is sporadic, and lacks clear connection to their business model (Tomsic et al., 2015; Lee et al., 2016; The European Observatory of SMEs, Martinez-Conesa et al. 2017). Several reasons are advanced for such observations. These include the scarcity of resources for deploying CSR initiatives and the unsystematic assignment of responsibilities for CSR implementation in small firms (Pastrana and Sriramesh, 2014; EU Commission, 2011) as opposed to large firms. On the whole, SMEs have fewer formal structures and looser control systems, less documentation on transactions (Beaver, 2002; Fassin, 2008) and higher aversion to administrative burdens (Fassin, 2008; Spence, 1999). Consequently, SMEs may not find it easy to derive performance outcomes from implementing CSR (Fassin, 2008; López-Pérez, 2017; Martinez-Conesa et al., 2017).

At the same time, management accounting researchers are calling for all types of companies, whether large or small, to integrate CSR into their management control systems $(M C S)^{2}$ (Henri \& Journeaut, 2010; Lisi, 2015). However, while the relationship between CSR and MCS is an emerging research theme in the accounting literature (Berry et al., 2009; Lueg \& Radlach, 2016), current research mainly concerns large organizations (Casadei \& Amadei, 2010; Curtzen et al., 2017). Moreover, few empirical studies have so far examined management accounting and control practices from the perspective of CSR (Günther et al. 2016; Crutzen et al. 2017), and the need for empirical research into the role of MCS in relation to CSR has been highlighted by several authors (Henri and Journeaut 2010; Arjaliès \& Mundy,

\footnotetext{
1 A CSR initiative may be qualified as strategic when it is "central to the firm's strategic mission, furnishes firm-specific benefits, and is visible to key external stakeholders" (Tetrault-Sirsly and Lamertz, 2008, p. 350). However, the statement that SMEs have CSR strategies and formal reporting of CSR may be a mere "fallacy" (Fassin, 2008). Therefore, we use the concept of initiative rather than strategy because an SME may not have a deliberate CSR strategy, or may be unaware of having it (Lee et al., 2016; Tomsic et al., 2015).

${ }^{2}$ MCS are the combinations of processes "by which managers influence other members of the organization to implement the organization's strategies" (Anthony and Govindarajan, 1998, p. 6).
} 
2013; Ghosh et al., 2019). Among the scant research on the relationship between CSR initiatives and MCS, most previous studies are dedicated to the environmental dimension of CSR and to specific dimensions of firm performance ${ }^{3}$ (e.g., Henri and Journeaut 2010; Lisi, 2015; Guenther et al., 2016). Hitherto, no single management accounting study, either of a qualitative or an empirical nature, has investigated SMEs (e.g., Henri and Journeaut, 2010; Gond et al., 2012; Arjaliès \& Mundy, 2013; Lisi, 2015; Hosoda \& Suzuki, 2015; Guenther et al., 2016).

In this paper, we respond to the calls to connect overall CSR and MCS (Lueg \& Radlach, 2016), and extend their scope by investigating the non-conventional field of SMEs (Crutzen, 2017), using a multi-dimensional construct to measure organizational performance 4 (Kirby, 2005; Richard et al., 2009). It is argued that the accounting literature should move from the what to the how, and its corollary, the integration of CSR into management accounting and control (Guenther et al., 2016; Maas et al., 2016). This is expected to help firms to achieve performance outcomes (Lisi, 2015; Crutzen, 2017). We posit that incorporating CSR into MCS will contribute to allying CSR initiatives with business strategies, effectively implementing these initiatives as well as measuring and communicating subsequent performance outcomes (Arjaliès \& Mundy, 2013; Gond et al., 2012; Lisi, 2015).

Accounting academics need to ask how MCS contribute to the effect of CSR initiatives on organizational performance; this is the key question (Durden, 2008; Gond et al., 2012; Lisi, 2015). Indeed, a number of researchers have called for an examination of the role of MCS - apparently essential but hitherto unexplored-as a mechanism for translating socio-environmental initiatives into performance outcomes (Lisi, 2015; Lueg \& Radlach, 2016). This paper is a response to such calls. In this sense, our study distinguishes itself by simultaneously considering the triumvirate of CSR-MCS-performance. Studies investigating the relationship between CSR and organizational performance, and that between CSR and MCS, have been focal in the CSR literature. However, a research gap has been identified, concerning, in particular, the role that CSR integration into MCS could play in mediating the above relationships. Interestingly, this study is the first in the literature to examine the intervening role that CSR integration into MCS can play in the association between CSR and SME performance. We propose an inclusive model to empirically examine the mediating role of CSR integration into MCS in the relationship between CSR initiatives and organizational performance.

In this study, further, we identify another gap in the literature; that is, the crucial observation across the CSR literature of a certain ambiguity regarding the roles of the MCS constituents. We discern through the literature a certain confusion over the roles of the artefact (i.e., the management control technology) ${ }^{5}$ and that of the

\footnotetext{
3 This phenomenon of focusing only on one or a few dimension(s) of performance (and neglecting the others) is not limited to the accounting research. Richard et al., (2009) find that single indicators of performance are used in $49 \%$ of the papers they reviewed across the top-five journals in management.

4 According to Richard et al., (2009, p. 719), "organizational performance is ultimate dependent variable of interest for researchers concerned with just about any area of management.".

5 Collins Dictionary defines technology as "methods and devices which are the result of scientific knowledge being used for practical purposes.".
} 
players (e.g., management accountants) ${ }^{6}$ who employ it in the context of CSR. Clarifying the mix-up between the human and the technological (Berry et al,. 2009) is necessary for analyzing the role of MCS in the association between CSR initiatives and organizational performance. This is also in line with the nascent research on micro-foundations of CSR (i.e., foundations of CSR that are based on individual action; Aguinis \& Glavas, 2012) and multi-level analysis that combines an organizational lens (e.g., MC technology) with an individual one (e.g., involvement of accountants) (Aguinis \& Glavas, 2012; Aguinis et al., 2011).

This paper also innovates by investigating such a role within SMEs rather than large firms, and in the context of an emerging country rather than a developed one (Tomsic et al., 2015; Martinez-Conesa et al., 2017). We posit that considering SMEs and emerging economies, such as Abu Dhabi (UAE), contributes to extending the current research on CSR accounting into new organizational and cultural settings (Arjaliès \& Mundy, 2013; Crutzen et al., 2017). According to Hofstede (1991), Middle Eastern (ME) people rely more than Western people on collective actions and direct contact. ME people may over-rely on a collective spirit, to the point where they find it easy to integrate business life and private life (Al Hadhrami, 2013). UAE's managers have been shown to favor participative approaches and human interactions over "calculative and Cartesian" tools such as those embedded in the accounting technology (House et al., 2004), and their consultative management style and conflict-avoidance approach (Grant et al., 2007; Al Hadhrami, 2013) may affect the integration of CSR into MCS.

The rest of the paper is organized in five sections. The development of hypotheses is discussed in Sect. 2, followed by methodology in Sect. 3. The findings are presented in Sect. 4. A discussion of the results and a conclusion are provided in Sects. 5 and 6 respectively, including implications for theory and practice, the limitations of the study, and suggestions for further research.

\section{Theoretical framework and hypotheses development}

\subsection{Background}

Several terms are used to designate the self-regulating activities of a company that acknowledge social accountability towards the various stakeholders. KPMG's report of 2013 reveals that $14 \%$ of the world's largest 100 firms use the term corporate responsibility, $25 \%$ use corporate social responsibility, and $43 \%$ use sustainability. In our paper, we use the term corporate social responsibility, considered by a number of accounting authors to be the primary nomenclature (Huang \& Watson, 2015).

The concept of CSR originally referred to that of business obligation as used by Frank Abrams, the chairman of the board of Standard Oil of New Jersey. In an article published in 1951 in the Harvard Business Review, he claimed that businesses have an

\footnotetext{
6 Throughout this paper, we follow Hartmann and Maas (2011) and use the job title management accountant to also designate that of a management controller.
} 
obligation "to conduct the affairs of the enterprise to maintain an equitable and workable balance among the claims of the various directly interested groups, a harmonious balance among stockholders, employees, customers, and the public at large" (Frederick, 2006). Two years later, Howard Bowen explicitly used the term CSR for the first time, in a book entitled The Social Responsibilities of the Businessman. Since then, the concept of CSR has evolved, and has been defined in many ways by researchers and regulators (Aguinis \& Glavas, 2012). In this paper, CSR is defined as "the firm's considerations of, and response to issues beyond the narrow economic, technical, and legal requirements of the firm to accomplish social and environmental benefits along with the traditional economic gains which the firm seeks" (Davis 1973, p. 312; Aguilera et al., 2007, pp. 836-837). The paper adopts this definition as it has received substantial approval from the scientific community, and is believed to be clear, comprehensive, and consensual.

The management of CSR initiatives under the constraints of value creation and the efficient use of resources requires a particular management control that goes beyond the traditional (Hosoda \& Suzuki, 2015). This is because of the particular nature of CSR initiatives (i.e., non-lucrative by definition, lacking codification and based on informal relationships; Martinez-Conesa et al., 2017). Specific management control is also needed to cope with the particularity of managerial intentions behind CSR investments (legitimacy seeking vs. rational decision-making), the strategic emphasis of CSR (a shift from owners/stockholders to stakeholders) (Lueg et Radlach 2016), the typicality of performance measures for the monitoring of CSR initiatives (often non-financial and intangible) (Maas et al., 2016), as well as the length of time required before the benefits, if any, of the CSR initiatives can be assessed (Durden, 2008). So far, little is known about the integration between sustainability performance measurement systems and the main MCS (Durden, 2008; Gond et al., 2012; Maas et al., 2016). A number of authors argue that performance measurement and control systems for CSR issues may remain marginal, unconnected to organizational business activities, and without influence on strategy (Gond et al., 2012; Lueg \& Radlach, 2016). It is argued that studies will undeniably benefit from focusing on the how, and its corollary, the integration, of CSR and management control (Guenther et al., 2016; Maas et al., 2016; Morioka \& Carvalho, 2016). To this end, we employ the concept of extent of integration of CSR into $M C S$, to acknowledge that such integration is a socio-technological process (Berry et al., 2009); we conceive of human intervention and technological intermediation as equally important.

\subsection{Research hypotheses}

In this section, we formulate the research hypotheses and specify the theoretical model. We recall from the above that this study contributes to relevant research by simultaneously focusing on the threefold relationship of CSR-MCS-performance. 


\subsubsection{CSR initiatives and organizational performance within SMEs}

The literature on the association between CSR and firm performance suggests a tenuous to highly positive relationship in terms of economic and non-economic benefits (Crifo et al., 2016; Hou, 2019; Kim et al., 2018; Rodgers et al., 2013). This has been documented in several review studies. For instance, Margolis et al., (2009) observe a small positive relationship between CSR and financial performance. The authors reviewed 251 studies (papers, books, dissertations, and working papers) that looked at the association between CSR and accounting-based or market-based measures of financial performance. Another review paper by Aguinis and Glavas (2012) reveals that sustainable development also has slight positive non-financial consequences at the institutional, organizational, and individual levels. But this positive association has ,not been fully established in the context of small firms (Fassin, 2008; Morsing \& Perrini, 2009). In the field of SMEs, the existence, and the nature of the association between CSR and performance, is even less clear (Lee et al., 2016; Morsing \& Perrini, 2009). The few existing studies show tenuous positive relationships; in particular, between CSR and financial performance (Niehm et al., 2008; Torugsa et al., 2012), CSR and innovation, and CSR and competitiveness (Battaglia et al., 2014; Martinez-Conesa et al., 2017).

While some academics affirm the existence of a positive association, especially with financial performance (Inoue \& Lee, 2011; Cvaco \& Crifo, 2014; Flammer, 2015; Crifo et al., 2016), a number of authors call for caution in accepting this conclusion. One stream of criticism points out that the CSR-performance relationship is either partial (Prado-Lorenzo et al., 2008) or curvilinear (Barnett \& Salomon, 2006), while a second stream denounces the failure to agree on measures of firm performance, the divergences in defining corporate responsibility, and the existence of measurement errors in empirical studies (Linnenluecke \& Griffiths, 2010; Lueg \& Radlach, 2016). Interestingly, Margolis et al. (2009) underline that the size of the positive relationship between CSR and financial performance has shrunk over the past few years. According to these authors, this may be an objective observation, or it may be a consequence of deploying more appropriate research methods.

With regard to the accounting literature, a deeper look also shows a focus on financial indicators of organizational performance, to the detriment of other performance aspects. Most relevant accounting articles highlight only the impact of CSR initiatives on financial indicators (El-Crutzen et al., 2017; Ghoul et al., 2011); even in review papers, there is evidence that accounting authors emphasize financial indicators (e.g., Huang \& Watson, 2015).

In summary, CSR initiatives are expected to be positively related to organizational performance (Aguinis \& Glavas, 2012). In our study, we argue that the definition of organizational performance is a surprisingly open question, with few studies using consistent measures (Kirby, 2005; Richard, 2009). Therefore, we build on seminal studies in management control (Chenhall \& Langfield-Smith, 2007; Kaplan \& Norton, 1996) and in management sciences (Quinn \& Rohrbaugh, 1983; Richard et al., 2009) and adopt a multi-item construct to measure organizational performance. The multi-item construct we adopt aims to allow for the assessment of the effect of CSR on overall organizational performance, rather than confinement 
to financial indicators. Our construct covers items belonging to a broad spectrum of organizational performance, including financial, environmental, and societal aspects. In doing so, the study aims to represent SMEs' broad organizational performance, as affected by CSR initiatives. This is in line with the recent studies on SMEs that depict a possible association between CSR and non-financial indicators (Battaglia et al., 2014; Martinez-Conesa et al., 2017), and may contribute to the current CSR literature by offering deeper insights into the effects of CSR initiatives on SMEs' organizational performance. This leads to $\mathrm{H}_{1}$ :

$\mathrm{H}_{1}$ : The extent of use of CSR initiatives is positively related to organizational performance in SMEs. ${ }^{7}$

\subsubsection{CSR initiatives and MCS}

As noted above, this study extends extant research by embedding two constituents of CSR integration into MCS; namely, management control technology (MCT) (i.e., techniques and methods) and the involvement of management accountants in CSR management (i.e., the human factor).

The relationship between the constructs of MCT and CSR initiatives is conflicted. While the former carries notions of profitability, productivity, and resource consumption, the latter conveys concepts of yield sharing, mutual benefits, and resource conservation (Lueg \& Radlach, 2016). These tensions may imply that CSR indicators such as environmental performance measures are perceived as hard to control or validate technically (Virtanen et al., 2013), which may be detrimental to firm performance (Lisi, 2015). It has been increasingly reported that firms use all types of MCT to control CSR issues, with the most heavily used types administrative controls (Lueg \& Radlach, 2016). However, these are mainly extensions of available control tools to CSR matters; as a remedy, researchers have suggested integrating CSR elements into management control to better control corporate CSR objectives (Durden, 2008; Lisi, 2015; Maas et al., 2016). This has given rise to eco-control, for example - the application of financial and strategic control methods to environmental management (Henri \& Journeault, 2010).

SMEs often fail to plan CSR goals and to measure CSR activities systematically. This is particularly relevant when it comes to accurately quantifying the value of CSR initiatives (Hayward et al., 2013). To address such shortcomings, academics have proposed approaches to integrating MCS with a firm's social responsibility objectives and outcomes (e.g., Durden, 2008; Maas et al., 2016).

In journal outlets dedicated to sustainability, an increasing number of researchers also speak of the need to integrate socio-environmental matters into design and use of performance measurement methods and tools (Morioka \& Carvalho, 2016; Schneider \& Meins, 2012). Commentators argue that such integration is critical for embedding sustainability in business strategy and management (Morioka \& Carvalho, 2016; Searcy, 2012).

The above analysis leads to $\mathrm{H}_{2 . \mathrm{a}}$ :

\footnotetext{
7 For brevity, in SMEs is presumed throughout the hypotheses.
} 
$\mathrm{H}_{\text {2.a }}$ The extent of CSR initiatives is positively related to the extent of integration of CSR into MCT.

Pava and Krausz (2007) and Durden (2008) highlight the need to involve accountants and controllers in CSR matters. In this vein, Carol (2009) calls for the accounting profession to help firms to meet their obligation to society and the planet. For commentators such as Huang and Watson (2015), it is obvious that accounting professionals (can) participate in the creation, assurance, issuance, and analysis of CSR reports. These authors point out that the responsibility for CSR reporting falls on accounting professionals; in particular, when a formal regulatory structure is missing. It is argued that the more strategic the organizational initiatives (e.g., CSR initiatives), the greater the need for the active involvement of controllers in the management of such initiatives (Hartmann \& Maas, 2011; Pasch, 2019; Zoni \& Merchant, 2007). One can posit that the more important the CSR initiatives for an organization, the greater the need for management controllers to guide the management of CSR initiatives (Caron and Fortin, 2014; Lueg \& Radlach, 2016):

$\mathbf{H}_{2 . b}$ The extent of CSR initiatives is positively related to the extent of involvement of management accountants in CSR management.

\subsubsection{MCS and organizational performance}

While a review of the literature reveals a small number of studies on the association between systems for measuring sustainability performance (in terms of techniques and methods) and financial performance, Lueg and Radlach (2016) conclude that the findings of these studies suggest a likely positive influence. The authors call for future research to explore the many open issues in the performance effects of integrating sustainability into MCS.

Critics claim that relevant research has brought scant evidence of the performance effects of MCS in the context of CSR (Arjaliès \& Mundy, 2013; Lueg \& Radlach, 2016). In addition, most extant studies focus on the environmental dimension of CSR, to the detriment of the social impacts (e.g., Henri \& Journeault, 2010; Lisi, 2015; Virtanen et al., 2013; Wisner et al., 2006). To date, the available evidence suggests a significant relationship between the integration of CSR into MCT and performance (Lisi, 2015; Maas et al., 2016). This is possible through the use of MC techniques and tools such as CSR metrics, CSR targets, CSR variance analysis, and CSR budgeting control. In this regard, Peloza (2009) finds that 59\% of 128 academic articles reviewed assert a relationship between adopting a measure/metric of social and environmental performance and financial performance.

The above review leads to the formulation of $\mathrm{H}_{3 . \mathrm{a}}$ :

$\mathbf{H}_{3 . a}$ The extent of integration of CSR into MCT is positively related to organizational performance. 
Performance measurement systems for sustainability per se cannot guarantee better performance (Dias-Sardinha et al., 2007; Lueg \& Radlach, 2016); it is through their activation by accountants and the interaction between such accountants and CSR that we can expect MCS to integrate CSR-related issues. In essence, MCS are socially enacted by means of artefacts, thanks to human intervention (Berry et al., 2009). Cases reported by researchers such as Durden (2008) show that whereas firms intentionally promote an image of social responsibility and try to behave in a socially responsible manner, they lack clear processes for making CSR an integral part of their strategic planning and operations. The involvement of management accountants in CSR management can help to address this weakness and allow firms to convert their good intentions into specific regular actions. Such involvement is operated through management controllers' core activities; namely, informationprocessing, cross-functional coordination, and formal planning (Erhart et al., 2017). In particular, we note again that early empirical studies on the organizational roles of controllers and accountants (Hopper, 1980; Simon et al., 1954) found that these players were not heavily involved in management processes. Since then, regardless of the organizational issues to be managed and types of decisions to be made, increasing evidence has confirmed that controller involvement in management is positively associated with firm performance (Zoni \& Merchant, 2007; Wolf et al., 2015). Several recent studies have probed the effects of involving accountants in CSR, and showed positive outcomes, particularly in terms of environmental performance (Albelda, 2011) and organizational commitment (Caron and Fortin, 2014).

$\mathbf{H}_{3 . b}$ The extent of involvement of management accountants in CSR management is positively related to organizational performance.

\subsubsection{Mediating role of CSR integration into management control in the CSR- performance relationship}

The literature reveals there are too few studies of the mechanisms through which the CSR-performance relationship operates (Huang \& Watson, 2015; Martinez-Conesa et al., 2017). For commentators (e.g., Lisi, 2015), little is yet known about the specific management accounting processes and systems whereby companies may translate their CSR orientation into improved performance. Indeed, researchers call for mediation studies to learn how CSR can be an important driving mechanism in making SMEs more innovative and effective (Martinez-Conesa et al., 2017). A survey of Canadian manufacturing firms by Henri and Journeault (2010) concludes that the integration of environmental concerns into management control has no direct influence on financial performance, but has a mediating effect on financial performance through its positive relations with environmental performance. In a recent review paper by Lueg and Radlach (2016), it is concluded that sustainability MCS foster only a slight consistent link from sustainable development to financial rewards and other kinds of compensation. Their study was based on a review of 83 studies published in 56 journals between 1988 and 2013. Sustainability MCS are essential for the integration of CSR (or sustainable development) with the social, environmental, 
and economic dimensions of businesses (Gond et al., 2012; Kaplan \& Norton, 1996; Lueg \& Radlach, 2016).

Some authors qualify that by socially responsible MCS (Durden, 2008), they mean the integration of environmental and/or social issues into MCS (i.e., environmental control systems as in Lisi (2015), eco-control systems, as in Henri and Journeault (2010); or sustainability MCS as in Lueg and Radlach (2016)). These systems are feasible because the lack or inadequacy of the metrics used for measuring CSR items is partly to blame for the fact that CSR contributes little or nothing to value creation among SMEs (Martinez-Conesa et al., 2017). Important technical and validity problems are raised when the available performance measurement systems are simply extended to CSR issues, instead of integrating these issues into the systems (Lisi, 2015; Maas et al., 2016; Virtanen et al., 2013). This sheds light on the importance of the technological dimension of MCS in making tangible and visible the value added by CSR initiatives (Lueg \& Radlach, 2016).

In addition, the findings in Arjaliès and Mundy (2013) clarify the problems encountered by companies in reconciling the long-term orientation of CSR strategy with the short-term perspective of financial performance. The authors suggest two reasons for such an observation: (i) the difficulties in measuring the return on CSR investments, which in turn accounts for the absence of CSR budgets, and (ii) a lack of executives' interest in CSR strategy beyond that required for purposes of legitimation. In such cases, one may expect skillful accountants to help in devising methods for measuring the return on investments in CSR, budgeting for CSR initiatives, and integrating compensation schemes. Huang and Watson (2015) add the contribution that accountants can make in terms of choosing key CSR performance indicators, preparing CSR reports, and providing CSR assurance, and note that, when accountants do make this contribution, they can directly or indirectly affect CSR outcomes.

It is argued that mediation occurs under two conditions (Abdel-Maksoud et al., 2016; Baron \& Kenny, 1986): first, an independent variable (x) affects a mediating variable $(\mathrm{M})$, and second, the mediating variable $(\mathrm{M})$ affects a dependent variable (Y). Hypotheses $\mathrm{H}_{1}$ and $\mathrm{H}_{2}$ above presume that the extent of using CSR initiatives is positively related to a firm's performance and that the former is positively related to the extent of the integration of CSR into MCT, and the involvement of management accountants in CSR management. Hypothesis $\mathrm{H}_{3}$ proposes that the integration of CSR into MCT and the involvement of management accountants in CSR management are related to firm performance. In our paper, we argue that the relationship between CSR initiatives and firm performance is mediated by CSR integration into MCT and/or the involvement of management accountants in CSR management. Hence, we hypothesize a mediating role of CSR integration into MCT and/ or the involvement of accountants in CSR management. Accordingly, the last of our hypotheses are as follows:

$\mathrm{H}_{\text {4.a }}$ The extent of integration of CSR into MCT mediates the relationship between CSR initiatives and organizational performance.

$\mathbf{H}_{4 . b}$ The extent of involvement of management accountants in CSR management mediates the relationship between CSR initiatives and organizational performance. 


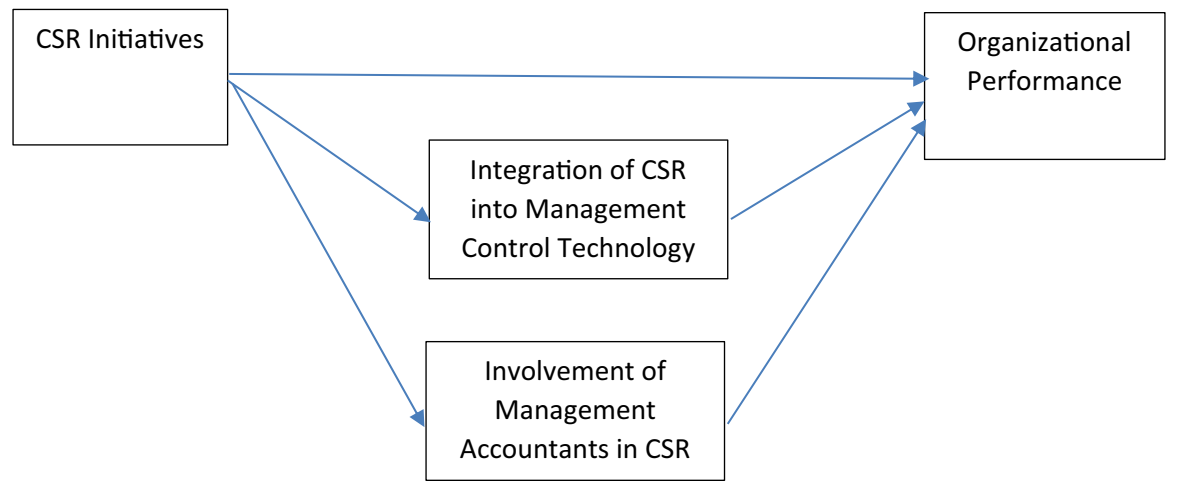

CONTROLS

Fig. 1 The study framework

The study framework is presented in Fig. 1 below.

The study adopts a contingency approach, which posits that no single best or universal control system exists, but that effective systems must be designed to fit a firm's organizational and environmental circumstances (Abdel-Maksoud et al., 2016). Further, the literature highlights the role of contingency theory in researching MCS and organizational performance (Hartmann, 2000). The research method is discussed next.

\section{Research method}

\subsection{The survey}

This paper follows a number of studies in the MCS literature (Widener, 2007; Arjelies and Mundy 2013) in deploying a questionnaire to offer a broad overview of the extent of integration of SMEs' CSR initiatives into MCS and the resulting performance outcomes. We respond to the call by a number of authors to investigate SMEs and to explore different national contexts (e.g., Arjaliès \& Mundy, 2013); investigating SMEs' initiatives in the Emirate of Abu Dhabi extends the scope of current research to new micro and macro contexts. Although CSR was initiated and fostered by Western businesses, the understanding of and behaviors towards CSR are contingent on the institutional environment of specific countries (Fifka \& Pobizhan, 2014). For commentators, the limited CSR studies set in emerging countries strengthen the view that differences in geographic, political, and economic settings trigger variations in the understanding of CSR initiatives and their measurement (Griesse, 2007; Zhu et al., 2016). The Emirate of Abu Dhabi offers an interesting national context in which to research because its CSR initiatives are shaped not only 
by its specific regulatory and normative settings but also by the frequent diversity of cultures and backgrounds of employees within its organizations.

In line with the novelty of the research phenomenon, we adopt non-random purposive sampling (Lisi, 2015). A total of 501 cross-sectional SMEs-listed in the directory of the Economic Development Authority of Abu Dhabi-comprised the final target sample. To ensure the most relevant data, the target recipient in each SME was the owner/general manager; we cross-checked that they all possessed sufficient information about the deployment of MCS and CSR initiatives. Data were collected through a web-based questionnaire administered to a target sample of SMEs operating across a variety of industries. To ensure the completion of the questionnaire, the web-based questionnaire was programmed in such a manner that respondents had to answer every question to be able to submit their questionnaire. The introduction section of the survey also informed the participants that they could tick a box if they wished to receive a summary of the results.

To improve response rate, we not only followed up the questionnaire by email and phone but also met the respondents on-site. This active strategy for collecting data led to the submission of 117 responses (23.3\%). This rate is comparable to relevant studies in the field of CSR management accounting and performance measurement that used a questionnaire method (see, e.g., Pondeville et al., 2013; Lisi, 2015).

We tested for potential non-response bias using the Mann-Whitney $U$-test (i.e., comparison between early and late responses; see Pollaned and Abdel-Maksoud, 2010; Dillman, 1978; Wallace \& Mellor, 1988). The comparison was carried out against a specific characteristic; namely, the size of the workforce. The results indicate that non-response bias was not present, thus posing no threat to the conclusions of this study (see Appendix 1).

\subsection{Measurement of variables}

Multi-item constructs were used in measuring the variables. The details of the construct measures are presented in Appendix 2.

\subsubsection{CSR initiatives}

The literature identifies numerous types of CSR initiatives as important in SMEs. Our study used 10 measurement items reflect2ing CSR initiatives, chosen on the basis of a careful literature review (El-Akremi et al., 2018; Farooq et al., 2017; Crifo et al., 2016; Pérez and Del Bosque, 2013; Pondeville et al. 2012; Arjaliès \& Mundy, 2013; Brammer et al., 2007). Appendix Table 5 shows the list of the 10 CSR items and the supporting literature. For the sake of parsimony, we collated the most common items used in previous studies (Martinez-Coneza et al. 2017; Crifo et al., 2016); thus, the items have the merit of summarizing the long list of CSR initiatives described in the extant literature while reflecting the range of SMEs' initiatives in reality. Overall, our CSR measure incorporates the majority of the aspects of the corporate responsibility. In addition to emphasizing philanthropic and community development activities (El-Akermmi et al., 2018; Rupp et al., 2013), we include 
CSR activities that are integrated into business processes such as ethical purchasing and investments, staff skill development, wellbeing of staff, recycling programs, control of carbon emission, conservation of water and energy, and other ecological initiatives (Henri et al., 2014; Norris \& O’Dwyer 2004; Park et al., 2014).

There are three reasons for emphasizing philanthropic and community development initiatives in measuring CSR. First, this is in line with most of the studies on the micro-foundations of CSR which underline such initiatives (see El-Akermi et al., 2018; Brammer et al., 2007; De Roeck and Farooq, 2018; Farooq et al., 2017; Rupp et al., 2013). Second, given the involvement of individuals as subjects in this study, we categorize this research as in the field of micro-foundations of CSR, which relies heavily on perceptual measures of CSR (Aguinis \& Glavas, 2012; Farooq et al., 2017; Rupp et al., 2013). Third, with the passage of time, some CSR activities have become an important part of the legal and normative framework that guides business practices. Most such activities revolve around environmental and labor laws (i.e., non-voluntary). For this reason, such activities may not fully reflect the CSR perceptions of the individuals, as they are considered compulsory for businesses.

Respondents were asked to assess the extent to which their organization was involved with CSR. Their response was expressed on a 5-point Likert scale ranging from 1: very low involvement to 5: very high involvement. The $10 \mathrm{CSR}$ items incorporated in our study covered ethical, social, and ecological initiatives.

\subsubsection{Integration of CSR into MCT}

The study then looked at the manner in which SMEs integrated CSR into their MC methods and techniques (Maas et al., 2016; Morioka \& Carvalho, 2016). Measurement items were selected based on a careful literature review. Given the shortage of an established scale for capturing the extent to which CSR is integrated into MCS, we designed an instrument that adapted items from relevant studies, particularly works that used a questionnaire method (Pondeville et al., 2013; Arjaliès \& Mundy, 2013; Lisi, 2015). A few items of the questionnaire were inspired by works that used case studies (Durden, 2008; Kaplan \& Norton, 1996; Morioka \& Carvalho, 2016). Overall, nine items were identified, as shown in Appendix Table 6. Examples of the items include "Our CSR initiatives are updated at the same time as the financial strategy," "Employees are encouraged to suggest ideas related to CSR and feedback is given," "Links between CSR initiatives AND financial strategy and customer strategy are known," and "CSR is implemented with a top-down approach (i.e., from our executives down to the shop floor level)." Respondents were asked to assess whether CSR was integrated into management control in their organizations, and were presented with a set of statements to which they could respond on a 5-point Likert scale ranging from 1: strongly disagree to 5: strongly agree.

\subsubsection{Involvement of management accountants in the management of CSR}

Respondents were next asked to assess the involvement of accountants in the management of CSR in their organization (Caron and Fortin 2013). Two classical levels of involvement (Bourne et al. 2000) were distinguished: in the construction 
(planning) and in the implementation and monitoring (controlling) of CSR objectives and policies (Durden, 2008; Searcy, 2012), where the latter involves ethical, social, and ecological aspects. Respondents were asked to assess such involvement using a 5-point Likert scale that ranged from 1: very low to 5: very high.

\subsubsection{Organizational performance}

Recall from Sect. 2.1 that our study builds on seminal studies in management control (Chenhall \& Langfield-Smith, 2007; Kaplan \& Norton, 1996, 2001) and management sciences (Quinn \& Rohrbaugh, 1983; Richard et al., 2009) and adopts a multi-item construct to measure organizational performance. Two approaches are recognized in the performance measurement literature to measure organizational performance: reported performance and perceived performance (Elbanna \& AbdelMaksoud, 2020; Franco-Santos et al., 2012). Reported performance concerns objective reported organizational performance measures, while perceived performance entails participants' perceptions of organizational performance (Elbanna \& AbdelMaksoud, 2020; Franco-Santos et al., 2012). In our study, we adopt a perceived performance approach to measure organizational performance, with a 16-item construct adapted from related CSR previous research. In doing so, we avoid confinement to financial indicators, and collate both financial and non-financial performance indicators (Chenhall \& Langfield-Smith, 2007; Richard et al., 2009; Singh et al., 2019). We adopt a multi-item construct (Quinn \& Rohrbaugh, 1983; Richard et al., 2009) that covers various financial and non-financial items, ${ }^{8}$ reflecting the balanced scorecard's four perspectives (Kaplan \& Norton, 2001) in addition to environmental and social performance indicators. The selection of these items aims to fit the SMEs' CSR domain of this study (Marin et al., 2012). Respondents were asked to assess their organization's performance for these 16 items using a 5-point Likert scale (ranging from 1: very poor to 5: very high).

\subsubsection{Control variables}

The paper recognizes that the associations between CSR, MCS, and performance are subject to the effects of a number of contextual variables. The variables selected for inclusion her-industry type, size of workforce, and public visibility measured by ownership type (Henri \& Journeault, 2010; Lisi, 2015; Journeault et al. 2016) were chosen because their influence is recognized in CSR and management control research.

Half of the surveyed firms (50\%) had fewer than 50 employees, $22 \%$ had between 50 and 250 employees, and $28 \%$ had over 250 employees. Almost two-thirds of the surveyed firms were privately owned (68\%), 22\% were semi-government-owned, and only $10 \%$ were government-owned. The respondents belonged to 11 industry

\footnotetext{
${ }^{8}$ See Appendix 2; Y1-Y3 are financial indicators, while Y4-Y16 are non-financial indicators.
} 
sectors $^{9}$; with the main industries represented including trading $(23 \%)$, manufacturing $(18 \%)$, leisure $(11 \%)$, and medical and pharmaceutical $(10 \%)$ and other services $(10 \%)$.

Untabulated results indicate that smaller firms (fewer than 50 employees) tend to have low involvement in CSR initiatives, while bigger firms (more than 50 employees) tend to have average to high involvement in CSR initiatives. Interestingly, a higher percentage of respondents from governmental organizations (89\%) reported average to high involvement in CSR initiatives compared with private and semigovernment respondents ( $75 \%$ and $76 \%$ respectively). The same tendency towards average to high firm involvement in CSR initiatives is evident among respondents belonging to the various industry sectors incorporated in our sample.

Statistical results indicate that only the size of the workforce has a significant association with the extent to which management accountants were involved in CSR management $(\beta=-0.115, \mathrm{t}=1.773, p<0.05)$. No other significant associations were reported for either of the other two control variables (industry type and ownership type). Data analysis and results are presented next.

\section{Data analysis and results}

Structural equation modeling (SEM) with partial least squares (PLS) analysis was used to analyze the data. ${ }^{10}$ To assess model stability, we used the $\mathrm{R}^{2}$ statistic; bootstrapping resampling was used to test for the significance of factor loadings and path coefficients (Abdel-Maksoud et al., 2016).

\subsection{Measurement model and validation of measure}

The PLS measurement model was adopted to evaluate the reliability (individual items and composite) and validity (convergent and discriminant) of the research. The PLS results and descriptive statistics are summarized in Table 1.

Individual item reliability was assessed using the factor loading of each item. The results in Table 1 show acceptable factor loadings of 0.7222 or more for all items. Composite reliability measures for all constructs ranged from 0.9354 to 0.9668 , which indicates an adequate composite reliability.

The constructs' average variance extracted (AVE) was used to assess the convergent validity of the measurement model (Hair et al. 2010). The AVEs for all the constructs are greater than 0.60 , ranging from 0.6175 to 0.8314 , which indicates good convergent validity. In addition, we assessed discriminant validity by checking that the square root of the AVE for each construct was greater than its correlation with other constructs (Hair et al. 2010). The results indicate adequate discriminant validity (see Table 2).

\footnotetext{
9 These consisted of manufacturing (18\%), construction (5\%), financial services (6\%), other services $(10 \%)$, energy $(3 \%)$, logistics $(3 \%)$, medical and pharmaceutical $(10 \%)$, leisure $(11 \%)$, trading $(23 \%)$, education (8\%), and environmental management (3\%).

${ }^{10}$ Smart PLS 2.3 software was used in the data analysis.
} 
Table 1 Reliability and convergent validity and AVE

\begin{tabular}{|c|c|c|c|c|c|c|}
\hline Latent variable & Min & $\operatorname{Max}$ & Mean & SD & $\begin{array}{l}\text { Factor } \\
\text { loadings }\end{array}$ & t-statistics \\
\hline \multicolumn{7}{|c|}{$X:$ CSR Initiatives (composite reliability $(C R)=0.9354 ; A V E=0.6175$ ) } \\
\hline $\mathrm{X} 1.2$ & 1 & 5 & 3.19 & 1.319 & 0.740574 & 14.587969 \\
\hline $\mathrm{X} 1.3$ & 1 & 5 & 2.88 & 1.347 & 0.722262 & 13.699847 \\
\hline $\mathrm{X} 1.4$ & 1 & 5 & 3.50 & 1.208 & 0.763897 & 16.914193 \\
\hline $\mathrm{X} 1.5$ & 1 & 5 & 3.26 & 1.372 & 0.777808 & 18.140743 \\
\hline X1.6 & 1 & 5 & 3.34 & 1.281 & 0.877562 & 35.863098 \\
\hline $\mathrm{X} 1.7$ & 1 & 5 & 3.55 & 1.141 & 0.779252 & 20.147463 \\
\hline $\mathrm{X} 1.8$ & 1 & 5 & 3.31 & 1.336 & 0.781661 & 18.023479 \\
\hline X1.9 & 1 & 5 & 3.17 & 1.379 & 0.838266 & 28.55409 \\
\hline $\mathrm{X} 1.10$ & 1 & 5 & 2.99 & 1.393 & 0.779739 & 17.950221 \\
\hline \multicolumn{7}{|c|}{ M_Tech: Integration of CSR into Management Control Technology $(C R=0.9640 ; A V E=0.7489)$} \\
\hline M_Tech_1.1 & 1 & 5 & 3.18 & 1.142 & 0.829005 & 19.505256 \\
\hline M_Tech_1.2 & 1 & 5 & 3.37 & 1.103 & 0.78666 & 13.941855 \\
\hline M_Tech_1.3 & 1 & 5 & 3.23 & 1.125 & 0.879291 & 31.401493 \\
\hline M_Tech_1.4 & 1 & 5 & 3.21 & 1.195 & 0.902334 & 41.189201 \\
\hline M_Tech_2.1 & 1 & 5 & 3.12 & 1.146 & 0.861161 & 24.858377 \\
\hline M_Tech_2.2 & 1 & 5 & 3.01 & 1.242 & 0.899626 & 50.396117 \\
\hline M_Tech_3.1 & 1 & 5 & 3.21 & 1.186 & 0.881183 & 41.468002 \\
\hline M_Tech_3.2 & 1 & 5 & 3.17 & 1.124 & 0.879645 & 40.261542 \\
\hline M_Tech_4.1 & 1 & 5 & 3.12 & 1.146 & 0.86355 & 20.795037 \\
\hline \multicolumn{7}{|c|}{ M_Inv: Involvement of Management Accountants in CSR Management $(C R=0.9517 ; A V E=0.8314)$} \\
\hline M_Inv_211 & 1 & 5 & 3.1709 & 1.19835 & 0.927781 & 64.48257 \\
\hline M_Inv_213 & 1 & 5 & 3.3761 & 1.16506 & 0.915004 & 55.849057 \\
\hline M_Inv_221 & 1 & 5 & 3.2479 & 1.12116 & 0.881334 & 31.111701 \\
\hline M_Inv_223 & 1 & 5 & 3.3504 & 1.08530 & 0.922407 & 52.690343 \\
\hline \multicolumn{7}{|c|}{ Y Organizational performance $(C R=0.9668 ; A V E=0.7090)$} \\
\hline Y4 & 1 & 5 & 3.62 & .989 & 0.768444 & 17.703956 \\
\hline Y5 & 1 & 5 & 3.95 & .981 & 0.819275 & 23.098606 \\
\hline Y6 & 1 & 5 & 3.64 & 1.118 & 0.786917 & 18.918933 \\
\hline Y7 & 1 & 5 & 3.66 & 1.001 & 0.888438 & 34.503907 \\
\hline Y8 & 1 & 5 & 3.69 & 1.046 & 0.893168 & 42.965215 \\
\hline Y9 & 1 & 5 & 3.56 & 1.118 & 0.864946 & 31.186606 \\
\hline Y10 & 1 & 5 & 3.63 & 1.022 & 0.920262 & 61.845061 \\
\hline Y11 & 1 & 5 & 3.46 & 1.149 & 0.813601 & 20.995057 \\
\hline $\mathrm{Y} 12$ & 1 & 5 & 4.01 & .996 & 0.801928 & 18.165388 \\
\hline Y13 & 1 & 5 & 3.56 & 1.086 & 0.870826 & 31.273431 \\
\hline Y14 & 1 & 5 & 3.82 & 1.103 & 0.835846 & 23.553416 \\
\hline Y15 & 1 & 5 & 3.97 & 1.042 & 0.826614 & 28.876568 \\
\hline Y16 & 1 & 5 & 3.60 & 1.153 & 0.768444 & 17.703956 \\
\hline
\end{tabular}

All item loadings on their respective constructs are statistically significant $(p<0.001$, one-tailed)

The following items were excluded from the constructs presented in Appendix 1 because they have a degree of freedom $<0.6$

X1.1., in 'CSR Initiatives (X)' construct; MD212 and 222 in 'Involvement of Management Accountants in CSR Management (M_Inv)' construct; Y1, Y2, and Y3 in 'Organization Performance (Y)' construct 
Table 2 Discriminant validity

\begin{tabular}{lllll}
\hline & X & M_Tech & M_Inv & Y \\
\hline X & $\mathbf{0 . 7 8 5 8}$ & & & \\
M_Tech & 0.6860 & $\mathbf{0 . 8 6 5 4}$ & & \\
M_Inv & 0.6059 & 0.6294 & $\mathbf{0 . 9 1 1 8}$ & \\
Y & 0.6846 & 0.5114 & 0.5699 & $\mathbf{0 . 8 4 2 0}$ \\
\hline
\end{tabular}

Bold values are square roots of AVE; off-diagonal elements are correlations between constructs

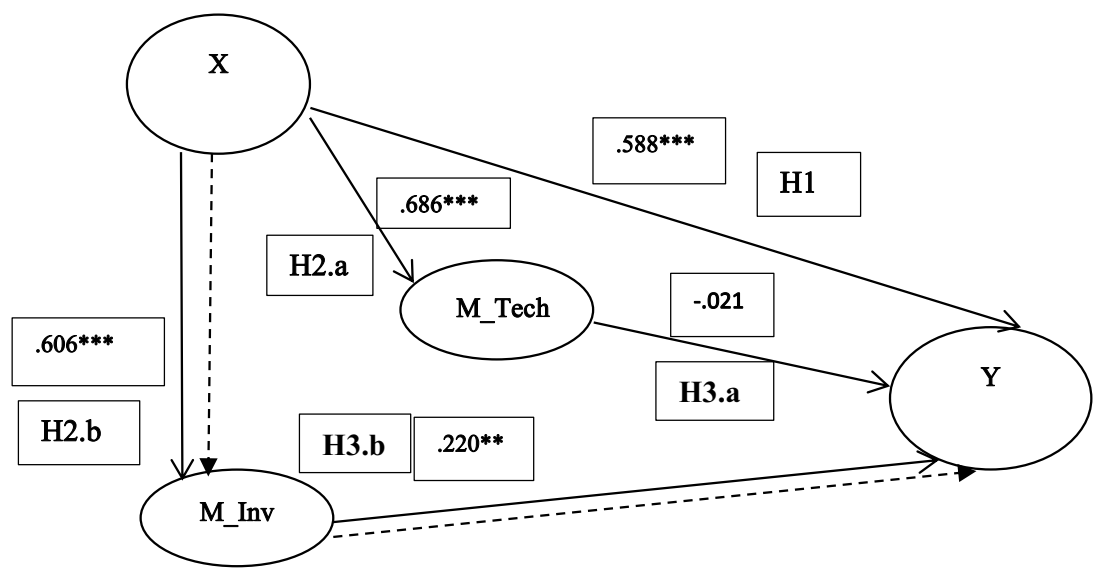

\section{Direct Relationship \\ Indirect Relationship}

Fig. 2 Results of the PLS structural model Note: $* p<0.05$; $* * p<0.01$; $* * * p<0.001$ ( one tailed); $\mathrm{N}=117, \mathrm{X}$ : CSR Initiatives, M-Tec: Integration of CSR into Management Control Technology, M-Inv: Involvement of Management Accountants in CSR management, Y: Organizational Performance

Since the data in this study were collected from single sources using self-reported measures, we tested for potential bias. Harman's single-factor test was used to assess any potential for common method variance (see Abdel-Maksoud et al. 2016; Podsakoff et al., 2003). The factor analysis results indicate a multi-factor solution, which poses no major threat to validity

\subsection{Structural model and hypotheses testing}

PLS structural equation models were used to test the study hypotheses. The results are presented in Fig. 2 and Table 3.

$\mathrm{H}_{1}$ predicts a significant positive association between the extent of using CSR initiatives and firm performance. As shown in Table 3, Panel A, the results indicate a significant path coefficient $(\beta=0.588, \mathrm{t}=7.486, p<0.001)$ for this relationship; hence, $\mathrm{H}_{1}$ is supported. 
Table 3 PLS structural model results

\begin{tabular}{|c|c|c|c|c|}
\hline \multirow[t]{3}{*}{ Latent variable } & \multicolumn{4}{|c|}{ Panel A: Path Coefficient, t-statistics (in parentheses), and $\mathrm{R}^{2}$} \\
\hline & \multicolumn{3}{|c|}{ Path coefficients (t-statistics) } & \multirow[t]{2}{*}{$\mathrm{R}^{2}$} \\
\hline & MC_Tech & ACCT_Inv & Y & \\
\hline $\mathrm{X}$ & $\begin{array}{l}0.686 \\
(14.553, \\
\quad p<0.001)^{* * *}\end{array}$ & $\begin{array}{l}0.606 \\
(9.800, p<0.001)^{* * * *}\end{array}$ & $\begin{array}{l}0.588 \\
(7.486, p<0.001)^{* * * *}\end{array}$ & - \\
\hline MC_Tech & - & - & $\begin{array}{l}-0.021 \\
(0.198)\end{array}$ & 0.471 \\
\hline ACCT_Inv & - & - & $\begin{array}{l}0.220 \\
(2.351, p<0.01)^{* *}\end{array}$ & 0.367 \\
\hline $\mathrm{Y}$ & - & - & - & 0.521 \\
\hline
\end{tabular}

Panel B: Indirect Effects and 90\%Bootstrap Confidence Intervals (in parentheses) ${ }^{\mathrm{a}}$

\begin{tabular}{lll}
\hline Latent Variable & Linkage & $\begin{array}{l}\text { Path to: } \\
\text { Organizational Performance (Y) }\end{array}$ \\
\hline CSR Initiatives (X) & M_Inv & $\begin{array}{l}\begin{array}{l}0.0293 \\
(0.0085353-0.229985) \\
-\end{array} \\
\end{array}$
\end{tabular}

Panel C: Total effect (t-statistics in parentheses)

\begin{tabular}{ll}
\hline Latent variable & $\begin{array}{l}\text { Path to: } \\
\text { Organizational Perfor- } \\
\text { mance (Y) }\end{array}$ \\
\hline CSR Initiatives $(\mathrm{X})$ & $\begin{array}{l}0.6846 \\
(11.0713, p<0.01)^{* *}\end{array}$ \\
\hline
\end{tabular}

$* p<0.05 ; * * p<0.01 * * * p<0.001$ (one tailed); $\mathrm{N}=117$

${ }^{\text {a }}$ To determine the significance of indirect effect, we used the bootstrap confidence interval estimation technique (see Hayes, 2009). Hayes argues that: “...if zero is not between the lower and upper bound, then the analyst can claim that the indirect effect is not zero with ci\% confidence. This is conceptually the same as rejecting the null hypothesis that the true indirect effect is zero at the ci \% level of significance" (Hayes, 2009, p. 412). Our results provide $90 \%$ confidence that the indirect effect is not zero; which infers a significant indirect effect at this level

$\mathrm{H}_{2}$ predicts a significant positive association between the extent of using CSR initiatives and the extent of integration of CSR into MCT (M_Tech) and involvement of management accountants in CSR management (M_Inv). The path coefficient is significant between CSR initiatives and M_Tech $(\beta=0.686, t=14.553, p<0.001)$ and M_Inv $(\beta=0.606, \mathrm{t}=9.800, p<0.001)$, indicating a positive association (see Table 3); hence, $\mathrm{H}_{2 . \mathrm{a}}$ and $\mathrm{H}_{2 . \mathrm{b}}$ are also supported.

$\mathrm{H}_{3}$ predicts a significant positive association between organizational performance and the extent of integration of CSR into MCT $\left(\mathrm{M}_{-}\right.$Tech $)\left(\mathrm{H}_{3 . \mathrm{a}}\right)$ and the involvement of management accountants in CSR management (M_Inv) $\left(\mathrm{H}_{3 . \mathrm{b}}\right)$. Interestingly, the results show the significance of the direct path leading from $\mathrm{M}$-Inv to firm performance $(Y)(\beta=0.220 ; t=2.442 ; p<0.01)$, supporting $\mathrm{H}_{3 . \mathrm{a}}$, but for the path leading 
from M_Tech to $Y$, results were not significant $(\beta=-0.021 ; t=0.203$; ins. $)$, and thus $\mathrm{H}_{3 . \mathrm{b}}$ is rejected.

\subsection{Mediation test}

Following the investigation of the direct hypotheses, the potential mediating effects of M_Tech and M_Inv on the relationship between CSR initiatives (X) and firm performance (Y) were examined (i.e., with reference to $\mathrm{H}_{4}$ ).

Three PLS models (in addition to the main model presented in Fig. 1 and Table 3, Panel A) were used to test whether M_Tech and M_Inv mediate the significant relationship between $\mathrm{X}$ and $\mathrm{Y}$. Mediation is supported if the following conditions exist (Baron \& Kenny, 1986): (i) significant relationships are found for the first two models, (ii) the third model shows that the mediating variable is related to the independent variable, and (iii) the relationship in the main model of the independent variable to the dependent variable (i.e., Fig. 1 and Table 3) is lower in magnitude than it is in the first model. However, to support full mediation, the independent variable (X) should not be related to the dependent variable (Y) when the mediating variables (M_Tech and M_Inv) are added to the main model.

The three models used to test for mediation are as follows:

The first model: The dependent variable (Y) was regressed on the independent variable $(\mathrm{X})$. This yielded a direct positive relationship $(\beta=0.701 ; \mathrm{t}=13.665$; $p<0.001)$, which supports a direct relationship between $\mathrm{X}$ and $\mathrm{Y}$.

The second model: The dependent variable (Y) was regressed separately on each mediating variable: (i) M_Tech and (ii) M_Inv. The results show a direct positive relationship between $M_{-}$Tech and $\mathrm{Y}(\beta=0.518 ; \mathrm{t}=8.056 ; p<0.001)$, and M_Inv and $\mathrm{Y}(\beta=0.556 ; \mathrm{t}=8.693 ; p<0.001)$. These results support a direct relationship between the dependent variable (Y) and the two mediating variables (M_Tech and M_Inv).

The third model: The mediating variables M_Tech and M_Inv were regressed on the independent variable $(\mathrm{X})$. The results support direct positive relationships between $X$ and $M \_T e c h(\beta=0.688 ; t=15.161 ; p<0.001)$ and $M \_I n v(\beta=0.603$; $\mathrm{t}=9.342 ; p<0.001)$.

Given the above results, we proceeded to determine the mediating effect of $\mathrm{M}_{-}$ Tech and M_Inv on the relationship between $\mathrm{X}$ and $\mathrm{Y}$. The results indicate that the significance of the direct path leading from $\mathrm{X}$ to $\mathrm{Y}$ changed when M_Inv (as mediator) was included in the main model; that is to say, the standardized coefficient and p-values fell from $(\beta=0.701 ; p<0.001)$ in the first model to $(\beta=0.588 ; p<0.001)$ in the main model (see Fig. 1 and Table 3, Panel A), which supports a partial mediation. Interestingly, the main model shows the significance of the direct path leading from $\mathrm{M} \_$Inv to $\mathrm{Y}(\beta=0.220 ; \mathrm{t}=2.442 ; p<0.01)$, but not the direct path leading from M_Tech to $\mathrm{Y}(\beta=-0.021 ; \mathrm{t}=0.203$; ins. $)$. Hence, $\mathrm{H}_{4 . \mathrm{a}}$ is rejected, while $\mathrm{H}_{4 . \mathrm{b}}$ is supported. That is, the significant direct relationship between $\mathrm{X}$ and $\mathrm{Y}$ is partially mediated by the involvement of management accountants in CSR management (i.e., 
M_Inv), but not by the integration of CSR into MCT (i.e., M_Tech). In other words, the results indicate that the human factor (i.e., accountants' involvement in CSR management) mediates the positive significant relationship between CSR initiatives and SMEs' performances in Abu Dhabi.

We further tested for the indirect effect of CSR initiatives on organizational performance, through the involvement of management accountants in CSR management. ${ }^{11}$ The results in Table 3, Panel B do indeed show a significant indirect association. Since the results indicate both direct and the indirect effects of CSR initiatives on organizational performance, we estimated the total effect (their sum). The results in Table 3, Panel $\mathrm{C}$ show that the total effect of CSR initiatives on organizational performance is significant $(\beta=0.6846 ; p<0.01)$.

\section{Discussion}

This study deployed a model that examined the mediating role played by CSR integration into MCS in the relationship between CSR initiatives and organizational performance in SMEs.

The results of our study contribute to the CSR literature and provide new insights. Hypothesis 1, on the effect of CSR initiatives on organizational performance, was fully supported by the data. The results show that the direct effect of CSR initiatives on organizational performance is significantly positive, confirming the findings of other studies (e.g., Crifo et al.,, 2016; López-Pérz, 2017; Martinez-Coneza, 2017). However, our research differs from these studies in that we extend their findings by (1) showing the very significant direct positive effect of CSR in the multi-item construct of organizational performance, and (2) further explaining the indirect effect of CSR initiatives on performance through the intervening construct of CSR integration in MCS.

Hypothesis 2 was also confirmed, since the findings show the direct positive effect of CSR initiatives on the integration of CSR into MCT and the involvement of management accountants in CSR management. A number of studies have shown how CSR positively influences constructs such as competitive advantage (Battaglia et al., 2014), firm value (Lima Crisóstomo et al., 2011), and corporate reputation (Park 2014), but no study, to the best of our knowledge, has investigated the effects on management control constituents. Hence, our paper extends these studies by showing a positive influence at the individual and organizational levels (Aguinis \& Glavas, 2012).

Hypothesis 3, concerning the effect of MCT and the involvement of management accountants in CSR management on organizational performance, was partially substantiated by the findings; that is, our findings show the involvement of accountants in CSR management as a determinant of organizational performance, though the integration of CSR into MCT was not shown to affect organizational performance.

\footnotetext{
11 It should be recalled that the results indicate no significant direct association between the integration of CSR into MCT (i.e., M_Tech) and organizational performance.
} 
This endorses the seminal call by Berry et al. (2009) to separate the technological and human facets of MCS.

Hypothesis 4 pertains to the mediating role that CSR integration into MCS (MCT and management accountants' involvement) plays in the relationship between CSR initiatives and SMEs' performance. The results demonstrate the mediating effect of accountants' involvement in the management of CSR. This finding implies that when a company is engaged in CSR initiatives, it involves its accountants in CSR management processes, with positive effects on SMEs' performance. On the contrary, we concluded that CSR integration into MCT has no mediating effect, since no significant direct relationship was reported between it and organizational performance. With these findings, which shed light on the underpinning processes explaining the relationship between CSR and organizational performance, our study makes a significant contribution to the literature. Exploring mediation mechanisms is very useful, for many reasons. Once a mediating process is identified, more efficient and powerful interventions can be developed because these interventions can focus on the variables in the mediating process (MacKinnon and Fairchild, 2009). Interventions are designed to change the outcome of interest by targeting the mediating variables hypothesized to be causally related to the outcome (MacKinnon et al., 2007). Mediators are those variables that affect predictor-related outcomes more proximally than the predictor itself, thus enabling practitioners to deploy interventions and change outcomes in relation to the variables that affect outcomes more proximally than distally (Hall, 2008).

Nevertheless, despite the importance of explaining mediation processes, very few studies trace the underpinning mechanisms. A significant body of literature on management studies highlights the positive effect of CSR on organizational performance (Crifo et al., 2016; Hou, 2019; Kim et al., 2018) but it is not sufficiently convincing to reach any conclusions on whether and how CSR initiatives affect organizational performance. Therefore, it has become vital to identify the mechanisms by which CSR initiatives exert such influence (Martinez-Conesa et al., 2017).

A handful of studies have examined the intervening role of organizational constructs in the relationship between CSR initiatives and the dimensions of organizational performance. For example, Hassan et al. (2018) studies the mediating role of productivity in the relationship between CSR and financial performance, while Carter (2005) demonstrates the mediation of organizational learning and supplier performance in the relationship between CSR and cost efficacy. Similarly, other studies have explained the mediation of reputation and customer satisfaction (Galbreath \& Shum, 2012; Saeidi et al., 2015) in the relationship between CSR initiatives and financial performance. Although these studies have undeniably contributed to the understanding of the relationship between CSR initiatives and performance, they have neither explained how CSR integration into MCS influences such a relationship nor considered the overall dimensions of organizational performance. Our study attempts to fill this gap by demonstrating how CSR initiatives influence organizational performance through the intervening roles of MCT and the involvement of management accountants in CSR management. 


\section{Conclusion}

This study proposed and empirically validated an inclusive model to examine the mediating role played by the integration of CSR into MCS in the relationship between CSR initiatives and SMEs' performance. The model embedded two constituents of CSR integration; namely, MCT and the involvement of management accountants in CSR management. The findings of this study have five considerable theoretical implications.

First, the results demonstrate that CSR initiatives have both direct and indirect positive effects on organizational performance. These findings show the mediation of the involvement of management accountants in CSR management in the relationship between CSR initiatives and organizational performance. However, we could not find any mediation role for MCT in the relationship between CSR initiatives and organizational performance. Such findings are consistent with the argument that individuals' related mechanisms help to explain the effects of MCS at the organizational level (Burney and Abdel-Maksoud et al., 2016; Ghosh et al., 2019; Hall, 2008; Widener, 2007). This also contributes to the nascent research stream on micro-foundations of CSR (i.e., foundations of CSR that are based on individual actions and interactions; Aguinis \& Glavas, 2012).

Second, the findings contribute to management control studies on the extended role of accounting employees' participation in a new organizational setting (e.g., Carol, 2009; Wolf et al. 2015); that is, the realm of CSR for SMEs. This study helps in understanding how MCS are important driving mechanisms for SMEs wishing to derive performance outcomes from deploying CSR initiatives. In particular, the paper shows the positive performance consequences of involving management accountants in CSR management.

Third, this paper is an attempt to address recent calls to adopt integrative perspectives in studying the triumvirate of CSR, MCS, and performance (e.g., Maas et al., 2016). As such, this study demonstrates how the integration of these constructs can help to understand how MCS are linked to CSR initiatives and how, in turn, they influence organizational performance.

Fourth, our study responds to calls to develop improved methods for examining the attributes of MCS (see Hall, 2008), by developing a reliable and valid instrument to measure the constructs of MCT and the involvement of management accountants and test their mediating role.

Fifth, this paper demonstrates the relevance of examining non-conventional contexts in management control. By focusing on SMEs within the Emirate of Abu Dhabi (UAE), we contribute to extending current research on CSR accounting and control to new organizational settings (Crutzen et al., 2017). Our findings indicate that the role of human intervention prevails over technology intermediation in conveying positive effects of CSR initiatives to performance. Two plausible explanations for this finding can be proffered.

The first may be particularly relevant to SMEs. Recall that our sample consists of the managers and owners of these firms. Given the greater proximity between managers and employees in SMEs than exists in large firms (Fuller, 2003), the 
usefulness of MCS may be seen by managers mainly through the prism of accountants' behaviors rather than through the contribution of the technology itself. Managers are essentially exposed to MCS through the human facet of these systems rather than the technological facet. The technological dimension may seem hidden or not directly observable by these players.

The second reason is intrinsic to the integration process of CSR into MCT. This process may still be in its early stages in terms of technological sophistication, in preparation for the effective and visible integration of CSR into MCS. Consequently, managers may limit their interaction with MCS to direct communication with management accountants, to the detriment of the exploitation of MCT (methods and techniques).

\subsection{Managerial and Policy Implications}

This study provides several policy implications for managers of SMEs, particularly within the context of an emerging economy (Abu Dhabi). The results of this study reveal that firm performance is influenced not only by purely commercial activities but also by CSR initiatives (López-Pérez, 2017). SMEs, struggling to remain afloat in today's ultra-competitive and dynamic environment, can improve their organizational performance by focusing on CSR (Crifo et al., 2016; Lima Crisóstomo et al., 2011). Interestingly, managers need to pay more attention to MCS since these turn out to be an essential mechanism via which to generate financial and non-financial benefits from deploying CSR initiatives.

Further, our findings reveal that CSR initiatives influence the integration of CSR into MCS within the SME workplace in the context of Abu Dhabi-UAE. As such, it is representative of emerging ME economies. Hence, CSR initiatives (and CSR integration) in the SMEs of this country would surely have implications for SMEs in other ME countries; in particular, the oil-rich Gulf Council Countries. This should further enhance the generalizability of our findings beyond the study context.

\subsection{Limitations of the study and future research directions}

Although this study followed rigorous methods, some limitations should be recognized. First, this study is limited by the selection processes for its variables and sample. Future research may apply a longitudinal design in any replication of this study, and could also extend the operationalization of organizational performance to multi-constructs, which would allow a deeper understanding of the impact of CSR initiatives on each organizational performance dimension (i.e., organization specific, environmental, and social). Second, data were collected using self-reported measures from single respondents; however, the results of testing for common method bias (see Sect. 4.1) indicated no threat from this. Third, the study is confined to Abu Dhabi-UAE, which limits generalization of the findings. Further studies could extend to include SMEs in other emerging economies. 
Despite these limitations, our study findings point to several avenues for future research. Our findings reveal that MCT does not play any role as a mediator; future research may explore other mediators, which may further clarify the process of mediation between CSR initiatives and organizational performance, as well as look at specific types of controls, in SMEs. Future studies may also consider investigating the effect of management's tendency to implement CSR initiatives - to satisfy specific stakeholders' pressure groups-which could influence configurating elements of MCT and involvement of management accountants in CSR management, which, in turn, influence organizational performance. We recommend use of objective secondary data, in particular for organizational performance, as this would extend the findings to objective organizational performance measures (e.g. Abdel-Maksoud et al., 2021). By focusing on SMEs and emerging economies, this research points to the relevance of studying nontraditional contexts in management control research. This being the case, we recommend future research to provide better understanding of effects of cultural traits on the role played by MCS in translating CSR initiatives into performance outcomes. Given the ongoing challenging global settings (e.g. COVID-19 pandemic), socio-managerial interdisciplinary research could further enrich SMEs literature - particularly, the inclusion of broader social contextual factors in CSR management in post-pandemic era. Furthermore, the UAE is widely regarded as being at the forefront of regional development (Elbanna \& Abdel-Maksoud, 2020); we recommend future research to consider comparing the CSR initiatives and integration in oil producing countries, in particular neighboring Gulf Countries Council, which will definitely enrich CSR's literature on SMEs in emerging economies.

\section{Appendix 1}

See Table 4 
Table 4 Results of the Mann-Whitney U-test

Null Hypothesis: (the distribution of size of the workforce Sig.* Decision
is the same across the categories)

\begin{tabular}{lll}
\hline 1 & 0.821 & Retain null hypotheses \\
2 & 0.217 & Retain null hypotheses \\
3 & 0.333 & Retain null hypotheses \\
4 & 0.063 & Retain null hypotheses \\
5 & 0.186 & Retain null hypotheses \\
6 & 0.702 & Retain null hypotheses \\
7 & 0.684 & Retain null hypotheses \\
8 & 0.663 & Retain null hypotheses \\
9 & 0.566 & Retain null hypotheses \\
10 & 0.716 & Retain null hypotheses \\
11 & 0.986 & Retain null hypotheses \\
\hline
\end{tabular}

* Significant level $=0.05$ at $95 \%$ confidence interval level

Group (1): Comparing between accumulated responses from week 12 with accumulated remaining responses;

Group (2): Comparison for accumulated responses from weeks 11 to 12;

Group (3): Comparison for accumulated responses from weeks 10 to 12;

Group (4): Comparison for accumulated responses from weeks 9 to 12 ;

Group (5): Comparison for accumulated responses from weeks 8 to 12 ;

Group (6): Comparison for accumulated responses from weeks 7 to 12 ;

Group (7): Comparison for accumulated responses from weeks 6 to 12;

Group (8): Comparison for accumulated responses from weeks 5 to 12 ;

Group (9): Comparison for accumulated responses from weeks 4 to 12 ;

Group (10): Comparison for accumulated responses from weeks 3 to 12;

Group (11): Comparison for accumulated responses from weeks 2 to 12

\section{Appendix 2}

\section{Constructs and Measures}

See Tables 5, 6, 7 and 8 


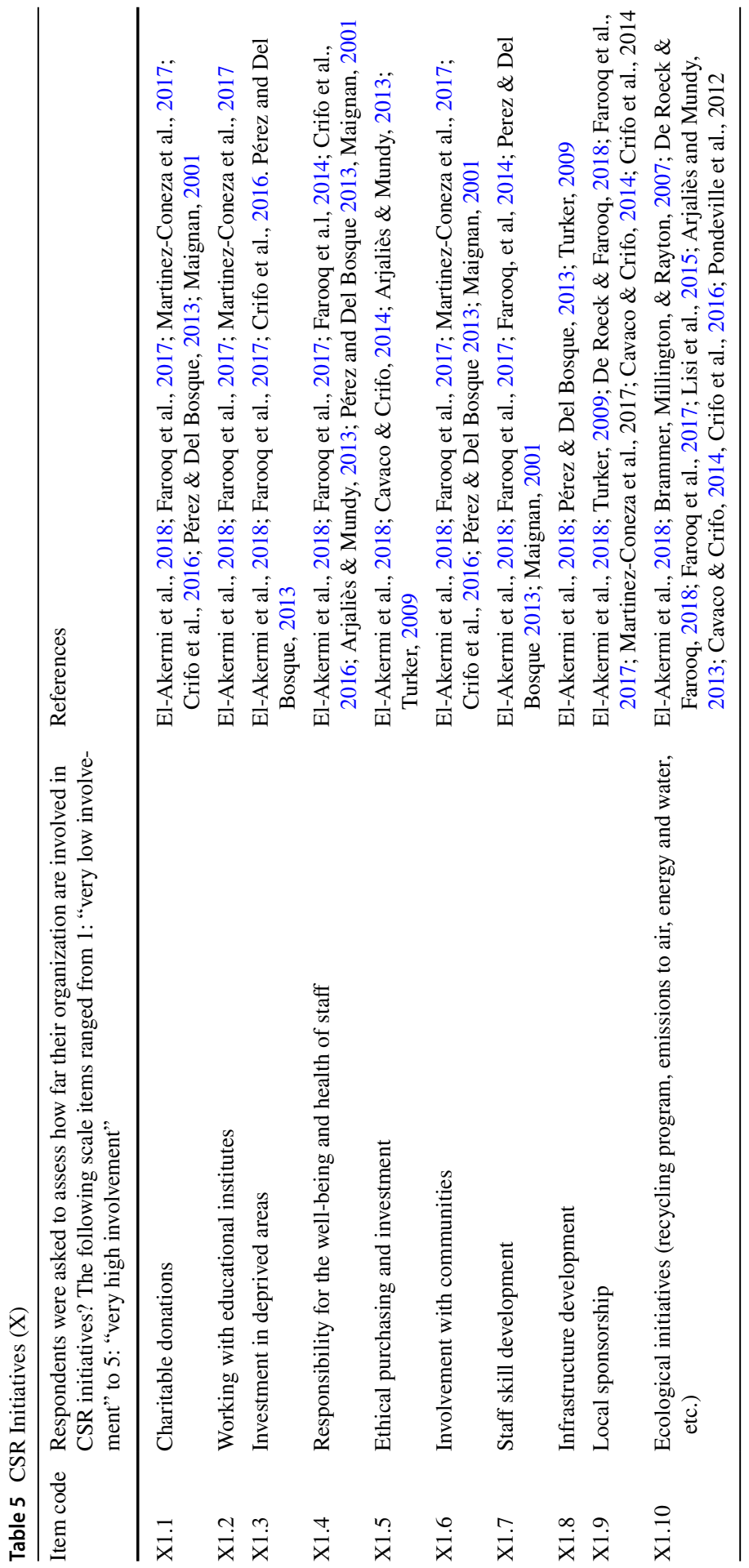




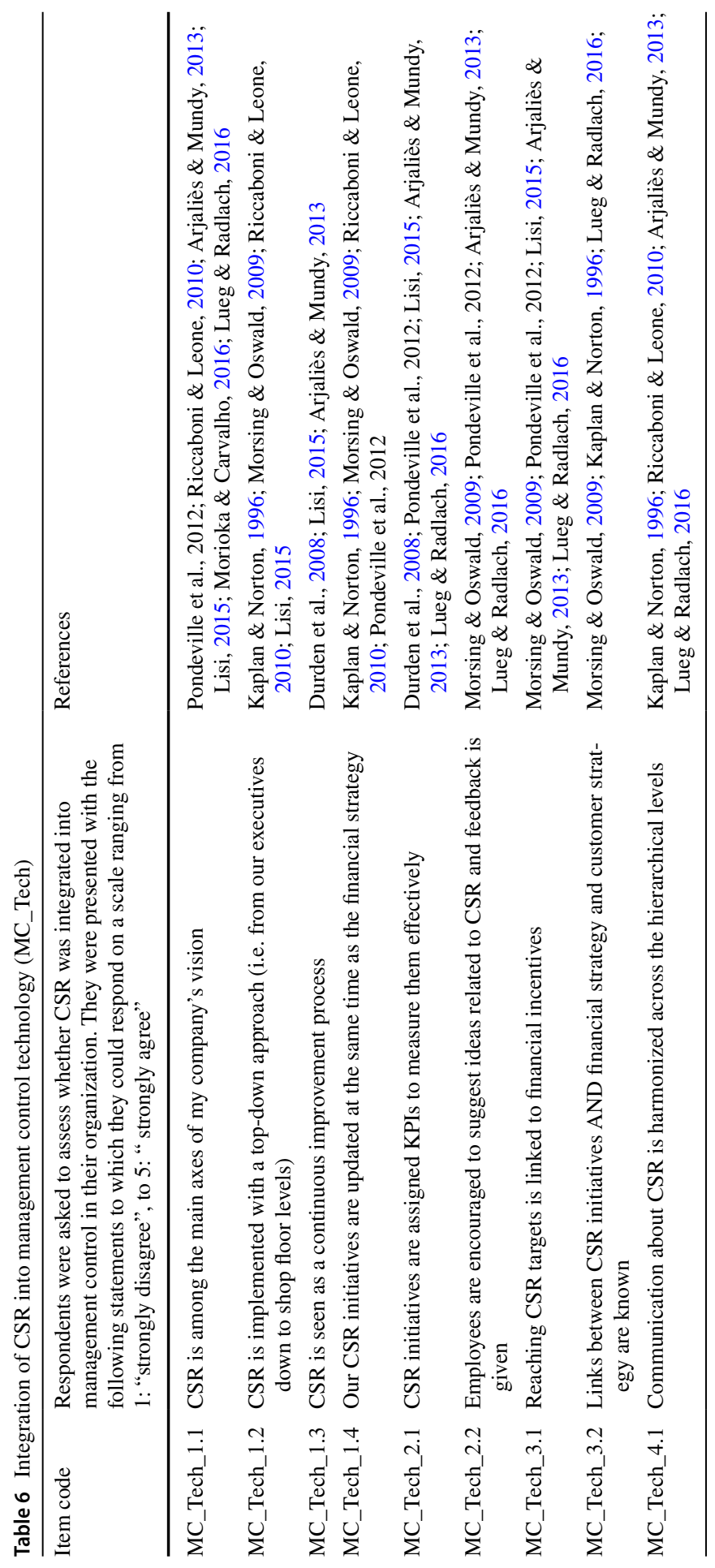




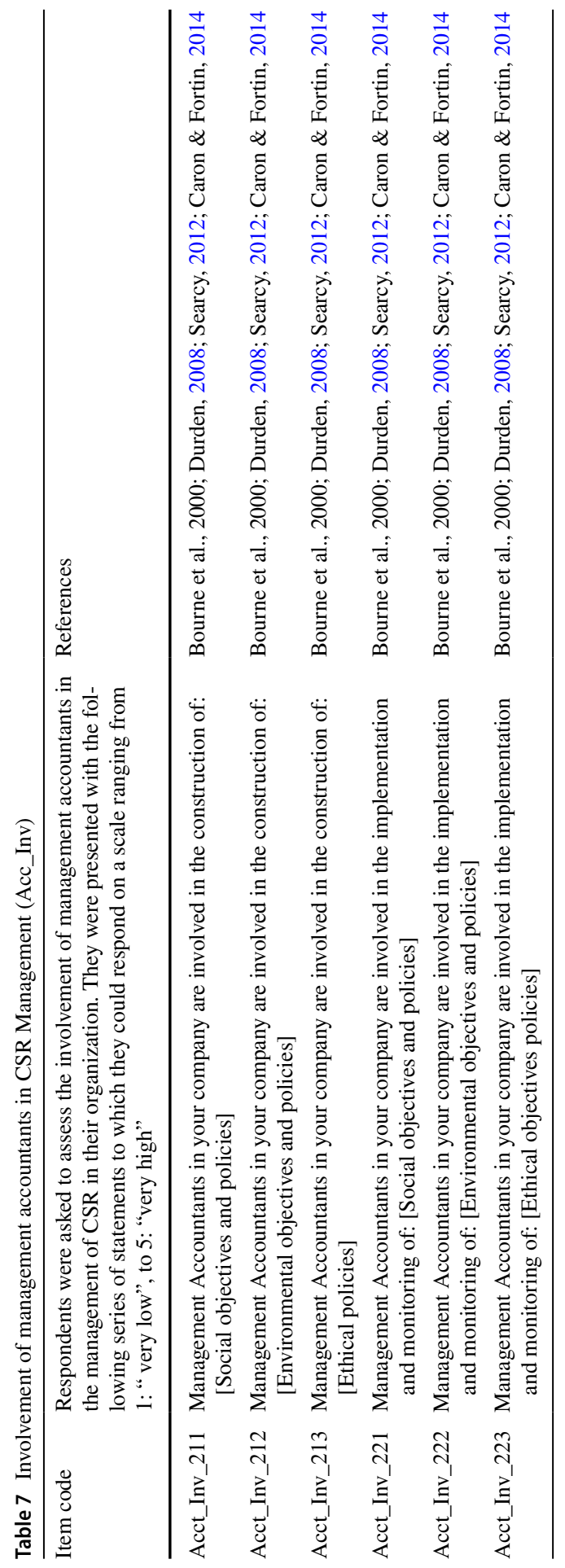




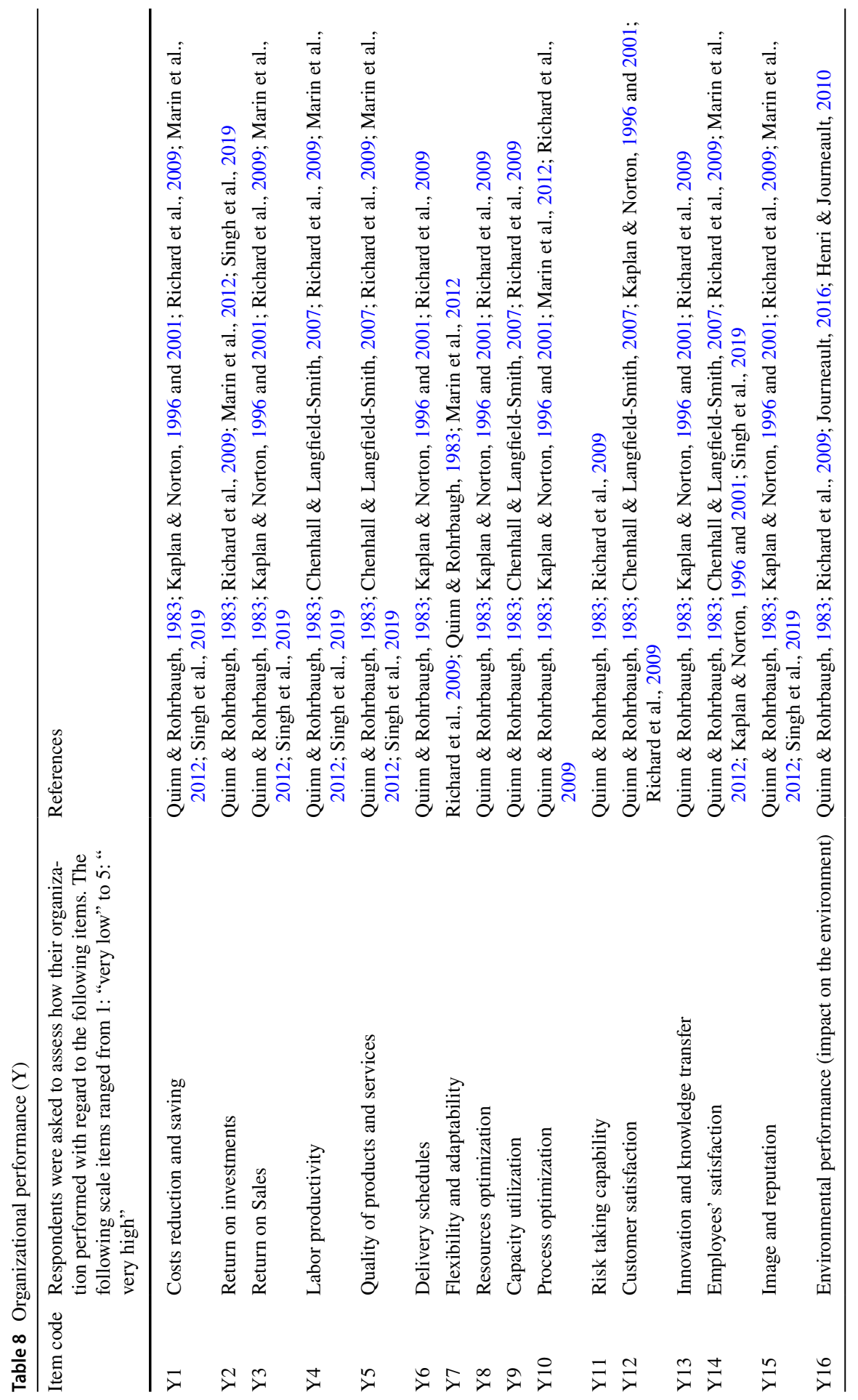




\section{Declarations}

Conflict of interest The authors declare that they have no conflict of interest.

Ethical approval The authors declare that they have complied with all ethical standards stated in the submission guidelines on the journal's webpage.

\section{References}

Abdel-Maksoud, A., Cheffi, W., \& Ghoudi, K. (2016). The mediating effect of shop-floor involvement on relations between advanced management accounting practices and operational non-financial performance indicators. The British Accounting Review, 48, 169-184.

Abdel-Maksoud, A., Jabbour, M., \& Abdel-Kader, M. (2021). Stakeholder pressure, eco-control systems, and firms' performance: Empirical evidence from UK manufacturers. Accounting Forum, 45(1), 30-57.

Aguilera, R. V., Rupp, D. E., Williams, C. A., \& Ganapathi, J. (2007). Putting the S back in corporate social responsibility: A multilevel theory of social change in organizations. Academy of Management Review, 32(3), 836-863.

Aguinis, H., \& Glavas, A. (2012). What we know and don't know about corporate social responsibility: A review and research agenda. Journal of Management, 38(4), 932-968.

Aguinis, H., Boyd, B. K., Pierce, C. A., \& Short, J. C. (2011). Walking new avenues in management research methods and theories: Bridging micro and macro domains. Journal of Management, 37 , $395-403$.

Albelda, E. (2011). The role of management accounting practices: evidence from EMAS organizations. Sustainability Accounting, Management and Policy Journal, 2(1), 76-100.

Alhadhrami, A. Z. M. B. (2013). UAE work environment examining the influences of culture, gender and sector on managerial leadership competencies, job satisfaction and organizational commitment (Doctoral dissertation, Curtin University).

Arjaliès, D. L., \& Mundy, J. (2013). The use of management control systems to manage CSR strategy: A levers of control perspective. Management Accounting Research, 24(4), 284-300.

Barnett, M. L., \& Salomon, R. M. (2006). Beyond dichotomy: The curvilinear relationship between social responsibility and financial performance. Strategic Management Journal, 27(11), 1101-1122.

Baron, R. M., \& Kenny, D. A. (1986). The moderator-mediator variable distinction in social psychological research: Conceptual, strategic, and statistical considerations. Journal of Personality and Social Psychology, 51(6), 1173.

Battaglia, M., Testa, F., Bianchi, L., Iraldo, F., \& Frey, M. (2014). Corporate social responsibility and competitiveness within SMEs of the fashion industry: Evidence from Italy and France. Sustainability, 6(2), 872-893.

Beaver, G. (2002). Small business, entrepreneurship and enterprise development. Prentice-Hall.

Berry, A. J., Coad, A. F., Harris, E. P., Otley, D. T., \& Stringer, C. (2009). Emerging themes in management control: A review of recent literature. The British Accounting Review, 41(1), 2-20.

Brammer, S., Millington, A., \& Rayton, B. (2007). The contribution of corporate social responsibility to organizational commitment.

Carol, A. (2009). Corporate responsibility, accounting and accountants. Professionals' perspectives of corporate social responsibility (pp. 11-32). Springer.

Caron, M., \& Fortin, A. (2014). Accountants' construction of CSR competencies and commitment. Sustainability Accounting, Management and Policy Journal, 5(2), 172-196.

Carter, C. R. (2005). Purchasing social responsibility and firm performance: The key mediating roles of organizational learning and supplier performance. International Journal of Physical Distribution and Logistics Management, 35(3), 177-194.

Casadei, A., \& Amadei, F. (2010). The competitive influence of corporate social responsibility and corporate social disclosure in Italian small and medium sized companies: Focus on disclosure and competitive drivers. Social and Environmental Accountability Journal, 30(1), 13-25.

Cavaco, S., \& Crifo, P. (2014). CSR and financial performance: Complementarity between environmental, social and business behaviours. Applied Economics, 46(27), 3323-3338. 
Chenhall, R. H., \& Langfield-Smith, K. (2007). Multiple perspectives of performance measures. European Management Journal, 25(4), 266-282.

EU Commission. (2011). A renewed EU strategy 2011-14 for Corporate Social Responsibility.

Crifo, P., Diaye, M., \& Pekovis, S. (2016). CSR related management practices and firm performance: An empirical analysis of the quantity-quality trade-off on French data. International Journal of Production Economics, 171(3), 405-416.

Crutzen, N., Zvezdov, D., \& Schaltegger, S. (2017). Sustainability and management control. Exploring and theorizing control patterns in large European firms. Journal of Cleaner Production, 143, 1291-1301.

De Roeck, K., \& Farooq, O. (2018). Corporate social responsibility and ethical leadership: Investigating their interactive effect on employees' socially responsible behaviors. Journal of Business Ethics, 151(4), 923-939.

Dias-Sardinha, I., Reijnders, L., \& Antunes, P. (2007). Developing sustainability balanced scorecards for environmental services: A study of three large Portuguese companies. Environmental Quality Management, 16(4), 13-34.

Dillman, D. A. (1978). Mail and telephone surveys: The total design method. Wiley.

Durden, C. (2008). Towards a socially responsible management control system. Accounting, Auditing and Accountability Journal, 21(5), 671-694.

Du, S., \& Vieira, E. T. (2012). Striving for legitimacy through corporate social responsibility: Insights from oil companies. Journal of Business Ethics, 110(4), 413-427.

El Akremi, A., Gond, J. P., Swaen, V., De Roeck, K., \& Igalens, J. (2018). How do employees perceive corporate responsibility? Development and validation of a multidimensional corporate stakeholder responsibility scale. Journal of Management, 44(2), 619-657.

Elbanna, S., \& Abdel-Maksoud, A. (2020). Organizational resources and performance: The case of an oil-rich country. Public Performance and Management Review, 43(3), 713-739.

El Ghoul, S., Guedhami, O., Kwok, C. C., \& Mishra, D. R. (2011). Does corporate social responsibility affect the cost of capital? Journal of Banking and Finance, 35, 2388-2406.

Erhart, R., Mahlendorf, M. D., Reimer, M., \& Schäffer, U. (2017). Theorizing and testing bidirectional effects: The relationship between strategy formation and involvement of controllers. Accounting, Organizations and Society, 61, 36-52.

Farooq, O., Payaud, M., Merunka, D., \& Valette-Florence, P. (2014). The impact of corporate social responsibility on organizational commitment: Exploring multiple mediation mechanisms. Journal of Business Ethics, 125(4), 563-580.

Farooq, O., Rupp, D. E., \& Farooq, M. (2017). The multiple pathways through which internal and external corporate social responsibility influence organizational identification and multifoci outcomes: The moderating role of cultural and social orientations. Academy of Management Journal, 60(3), 954-985.

Fassin, Y. (2008). SMEs and the fallacy of formalising CSR. Business Ethics: a European Review, 17(4), 364-378.

Fifka, M. S., \& Pobizhan, M. (2014). An institutional approach to corporate social responsibility in Russia. Journal of Cleaner Production, 82, 192-201.

Flammer, C. (2015). Does corporate social responsibility lead to superior financial performance? A regression discontinuity approach. Management Science, 61(11), 2549-2568.

Franco-Santos, M., Lucianetti, L., \& Bourne, M. (2012). Contemporary performance measurement systems: A review of their consequences and a framework for research. Management Accounting Research, 23(2), 79-119.

Frederick, W. (2006). Corporation, be good! The story of corporate social responsibility. Dog Ear Publishing.

Fuller, T. (2003). If you wanted to know the future of small business what questions would you ask? Futures, 35(4), 305-32.

Galbreath, J., \& Shum, P. (2012). Do customer satisfaction and reputation mediate the CSR-FP link? Evidence from Australia. Australian Journal of Management, 37(2), 211-229.

Ghosh, B., Herzig, C., \& Mangena, M. (2019). Controlling for sustainability strategies: findings from research and directions for the future. Journal of Management Control, 30(1), 5-24.

Gond, J.-P., Grubnic, S., Herzig, C., \& Moon, J. (2012). Configuring management control systems: theorizing the integration of strategy and sustainability. Management Accounting Research, 23(3), 205-223.

Govindarajan, V., \& Anthony, R. N. (1998). Management control systems. Irwin McGraw-Hill. 
Grant, J., Golawala, F. S., \& McKechnie, D. S. (2007). The United Arab Emirates: The twenty-first century beckons. Thunderbird International Business Review, 49(4), 507-533.

Griesse, M. A. (2007). The geographic, political, and economic context for corporate social responsibility in Brazil. Journal of Business Ethics, 73, 21-37.

Guenther, E., Endrikat, J., \& Guenther, T. W. (2016). Environmental management control systems: a conceptualization and a review of the empirical evidence. Journal of Cleaner Production, 136, $147-171$.

Hall, M. (2008). The effect of comprehensive performance measurement systems on role clarity, psychological empowerment and managerial performance. Accounting, Organizations and Society, $33(2-3), 141-163$.

Hartmann, F. G. (2000). The appropriateness of RAPM: toward the further development of theory. Accounting, Organizations and Society, 25(4-5), 451-482.

Hartmann, F. G. H., \& Maas, V. S. (2011). The effects of uncertainty on the roles of controllers and budgets: An exploratory study. Accounting and Business Research, 41(5), 439-458.

Hasan, I., Kobeissi, N., Liu, L., \& Wang, H. (2018). Corporate social responsibility and firm financial performance: The mediating role of productivity. Journal of Business Ethics, 149(3), 671-688.

Hayward, R., Lee, J., Keeble, J., McNamara, R., Hall, C., Cruse, S., Gupta, P., \& Robinson, E. (2013). The UN global compact-accenture CEO study on sustainability 2013. UN Global Compact Reports, 5(3), 1-60.

Henri, J. F., \& Journeault, M. (2010). Eco-control: The influence of management control systems on environmental and economic performance. Accounting, Organizations and Society, 35(1), 63-80.

Henri, J. F., Boiral, O., \& Roy, M. J. (2014). The tracking of environmental costs: motivations and impacts. European Accounting Review, 23(4), 647-669.

Hofstede, G. (1991). Organizations and cultures: Software of the mind. McGrawHill.

Hopper, T. (1980). Role conflicts of management accountants and their position within organisation structures. Accounting, Organizations and Society, 5(4), 401-411.

Hosoda, M., \& Suzuki, K. (2015). Using management control systems to implement CSR activities: an empirical analysis of 12 Japanese companies. Business Strategy and the Environment, 24(7), $628-642$.

Hou, T. (2019). The relationship between corporate social responsibility and sustainable financial performance: Firm-level evidence from Taiwan. Corporate Social Responsibility and Environmental Management, 26, 19-28.

House, R. J., Hanges, P. J., Javidan, M., Dorfman, P. W., \& Gupta, V. (2004). Leadership, culture, and organizations: The GLOBE study of 62 societies. Sage Publications.

Huang, X. B., \& Watson, L. (2015). Corporate social responsibility research in accounting. Journal of Accounting Literature, 34, 1-16.

Inoue, Y., \& Lee, S. (2011). Effects of different dimensions of corporate social responsibility on corporate financial performance in tourism-related industries. Tourism Management, 32(4), 790-804.

Journeault, M. (2016). The influence of the eco-control package on environmental and economic performance: A natural resource-based approach. Journal of Management Accounting Research, 28(2), $149-178$.

Kaplan, R. S., \& Norton, D. P. (1996). The balanced scorecard: Translating strategy into action. Harvard Business School Press.

Kaplan, R. S., \& Norton, D. P. (2001). The strategy-focused organization: How balanced scorecard companies thrive in the new business environment. Harvard Business School Press.

Kim, K.-H., Kim, M., \& Qian, C. (2018). Effects of corporate social responsibility on corporate financial performance: A competitive-action perspective. Journal of Management, 44(3), 1097-1118.

Kirby, J. (2005). Toward a theory of high performance. Harvard Business Review, 83, 30-39.

Lee, K. H., Herold, D. M., \& Yu, A. L. (2016). Small and medium enterprises and corporate social responsibility practice: A Swedish perspective. Corporate Social Responsibility and Environmental Management, 23(2), 88-99.

Lima Crisóstomo, V., de Souza Freire, F., \& Cortes de Vasconcellos, F. (2011). Corporate social responsibility, firm value and financial performance in Brazil. Social Responsibility Journal, 7(2), 295-309.

Linnenluecke, M. K., \& Griffiths, A. (2010). Corporate sustainability and organizational culture. Journal of World Business, 45(4), 357-366.

Lisi, I. E. (2015). Translating environmental motivations into performance: The role of environmental performance measurement systems. Management Accounting Research, 29, 27-44. 
López-Pérez, M. E., Melero, I., \& Javier Sese, F. (2017). Management for sustainable development and its impact on firm value in the SME context: Does size matter?. Business Strategy and the Environment, 26(7), 985-999.

Lueg, R., \& Radlach, R. (2016). Managing sustainable development with management control systems: A literature review. European Management Journal, 34(2), 158-171.

Maas, K., Schaltegger, S., \& Crutzen, N. (2016). Integrating corporate sustainability assessment, management accounting, control, and reporting. Journal of Cleaner Production, 136, 237-248.

MacKinnon, D. P., \& Fairchild, A. J. (2009). Current directions in mediation analysis. Current directions in psychological science, 18(1), 16-20.

MacKinnon, D. P., Fairchild, A. J., \& Fritz, M. S. (2007). Mediation analysis. Annu Re Psychol, 58, 593-614.

Maignan, I. (2001). Consumers' perceptions of corporate social responsibilities: A cross-cultural comparison. Journal of business ethics, 30(1), 57-72.

Margolis, J. D., Elfenbein, H. A., \& Walsh, J. P. (2009). Does it pay to be good ... And Does it Matter? A meta-analysis of the relationship between corporate social and financial performance (March 1, 2009). SSRN: https://ssrn.com/abstract $=1866371$.

Marín, L., Rubio, A., \& de Maya, S. R. (2012). Competitiveness as a strategic outcome of corporate social responsibility. Corporate Social Responsibility and Environmental Management, 19(6), 364-376.

Martinez-Conesa, I., Soto-Acosta, P., \& Palacios-Manzano, M. (2017). Corporate social responsibility and its effect on innovation and firm performance: An empirical research in SMEs. Journal of Cleaner Production, 142, 2374-2383.

Morioka, S. N., \& Carvalho, M. M. (2016). Measuring sustainability in practice: exploring the inclusion of sustainability into corporate performance systems in Brazilian case studies. Journal of Cleaner Production, 136, 123-133.

Morsing, M., \& Oswald, D. (2009). Sustainable leadership: management control systems and organizational culture in Novo Nordisk A/S. Corporate Governance: The International Journal of Business in Society, 9(1), 83-99.

Morsing, M., \& Perrini, F. (2009). CSR in SMEs: Do SMEs matter for the CSR agenda? Business Ethics: A European Review, 18(1), 1-6.

Niehm, L. S., Swinney, J., \& Miller, N. J. (2008). Community social responsibility and its consequences for family business performance. Journal of Small Business Management, 46(3), 331-350.

Norris, G., \& O'Dwyer, B. (2004). Motivating socially responsive decision-making: The operation of management controls in a socially responsive organisation. The British Accounting Review, 36(2), 173-196.

Park, J., Lee, H., \& Kim, C. (2014). Corporate social responsibilities, consumer trust and corporate reputation: South Korean consumers' perspectives. Journal of Business Research, 67(3), 295-302.

Pasch, T. (2019). Strategy and innovation: the mediating role of management accountants and management accounting systems' use. Journal of Management Control, 30, 231-246.

Pastrana, N. A., \& Sriramesh, K. (2014). Corporate social responsibility: Perceptions and practices among SMEs in Colombia. Public Relations Review, 40(1), 14-24.

Pava, M. L., \& Krausz, J. (2007). The broadening scope of corporate accountability: Some unanswered questions. In J. Allouche (Ed.), Corporate social responsibility.Palgrave Macmillan.

Peloza, J. (2009). The challenge of measuring financial impacts from investments in corporate social performance. Journal of Management, 35(6), 1518-1541.

Pérez, A., \& Del Bosque, I. R. (2013). Measuring CSR image: three studies to develop and to validate a reliable measurement tool. Journal of business ethics, 118(2), 265-286.

Podsakoff, P. M., MacKenzie, S. B., Lee, J. Y., \& Podsakoff, N. P. (2003). Common method biases in behavioral research: a critical review of the literature and recommended remedies. Journal of applied psychology, 88(5), 879.

Pollanen, R., \& Abdel-Maksoud, A. (2010). The deployment of contemporary management accounting practices in Canadian firms: A contingency approach. International Journal of Managerial and Financial Accounting., 2, 134-152.

Pondeville, S., Swaen, V., \& De Rongé, Y. (2013). Environmental management control systems: The role of contextual and strategic factors. Management accounting research, 24(4), 317-332.

Prado-Lorenzo, J. M., Gallego-Álvarez, I., García-Sánchez, I. M., \& Rodríguez-Domínguez, L. (2008). Social responsibility in Spain: Practices and motivations in firms. Management Decision, 46(8), 1247-1271. 
Quinn, R. E., \& Rohrbaugh, J. (1983). A spatial model of effectiveness criteria: Towards a competing values approach to organizational analysis. Management Science, 29(3), 363-377.

Riccaboni, A., \& Leone, E. L. (2010). Implementing strategies through management control systems: The case of sustainability. International Journal of Productivity and Performance Management, 59(2), 130-144.

Richard, P. J., Devinney, T. M., Yip, G. S., \& Johnson, G. (2009). Measuring organizational performance: Towards methodological best practice. Journal of Management, 35(3), 718-804.

Rodgers, W., Choy, H. L., \& Guiral, A. (2013). Do investors value a firm's commitment to social activities? Journal of Business Ethics, 114(4), 607-623.

Rupp, D. E., Shao, R., Thornton, M. A., \& Skarlicki, D. P. (2013). Applicants' and employees' reactions to corporate social responsibility: The moderating effects of first-party justice perceptions and moral identity. Personnel Psychology, 66(4), 895-933.

Saeidi, S. P., Sofian, S., Saeidi, P., Saeidi, S. P., \& Saaeidi, S. A. (2015). How does corporate social responsibility contribute to firm financial performance? The mediating role of competitive advantage, reputation, and customer satisfaction. Journal of Business Research, 68(2), 341-350.

Schneider, A., \& Meins, E. (2012). Two dimensions of corporate sustainability assessment: Towards a comprehensive framework. Business Strategy and the Environment, 21(4), 211-222.

Searcy, C. (2012). Corporate sustainability performance measurement systems: A review and research agenda. Journal of Business Ethics, 107(3), 239-253.

Simon, H. A., Kozmetsky, G., Guetzkow, H., \& Tyndall, G. (1954). Centralization vs Decentralization in Organizing the Controller's Department. New York, NY: The Controllership Foundation.

Singh, S. K., Gupta, S., Busso, D., \& Kamboj, S. (2019). Top management knowledge value, knowledge sharing practices, open innovation and organizational performance. Journal of Business Research, $128,788-198$.

Spence, L. (1999). Does size matter? The state of the art in small business ethics. Business Ethics: A European Review, 8(3), 163-174.

Tetrault-Sirsly, C. A., \& Lamertz, K. (2008). When does a corporate social responsibility initiative provide a first-mover advantage? Business and Society, 47(3), 343-369.

Tomšič, N., Bojnec, Š, \& Simčič, B. (2015). Corporate sustainability and economic performance in small and medium sized enterprises. Journal of Cleaner Production, 108, 603-612.

Torugsa, N. A., O’Donohue, W., \& Hecker, R. (2012). Capabilities, proactive CSR and financial performance in SMEs: Empirical evidence from an Australian manufacturing industry sector. Journal of business ethics, 109(4), 483-500.

Turker, D. (2009). Measuring corporate social responsibility: A scale development study. Journal of business ethics, 85(4), 411-427.

Virtanen, T., Tuomaala, M., \& Pentti, E. (2013). Energy efficiency complexities: A technical and managerial investigation. Management Accounting Research, 24(4), 401-416.

Wallace, R. S., \& Mellor, C. J. (1988). Non-response bias in mail accounting surveys: A pedagogical note. British Accounting Review, 20, 131-139.

Widener, S. K. (2007). An empirical analysis of the levers of control framework. Accounting, Organizations and Society, 32(7-8), 757-788.

Wisner, P., Epstein, M., \& Bagozzi, R. (2006). Organizational antecedents and consequences of environmental performance. In M. Freedman \& B. Jaggi (Eds.), Advanced in environmental accounting and management. (Vol. 3). Elsevier.

Wolf, S., Weißenberger, B. E., Wehner, M. C., \& Kabst, R. (2015). Controllers as business partners in managerial decision-making. Journal of Accounting and Organizational Change.

Zhu, Q., Liu, J., \& Lai, K. H. (2016). Corporate social responsibility practices and performance improvement among Chinese national state-owned enterprises. International Journal of Production Economics, $171,417-426$.

Zoni, L., \& Merchant, K. A. (2007). Controller involvement in management: an empirical study in large Italian corporations. Journal of Accounting and Organizational Change, 3(1), 29-43.

Publisher's Note Springer Nature remains neutral with regard to jurisdictional claims in published maps and institutional affiliations. 


\section{Authors and Affiliations}

\section{Walid Cheffi ${ }^{1}\left[\right.$ - Ahmed Abdel-Maksoud ${ }^{1} \cdot$ Muhammad Omer Farooq $^{1}$}

Ahmed Abdel-Maksoud

ahmed.abdel-maksoud@zu.ac.ae

Muhammad Omer Farooq

muhammad.farooq@zu.ac.ae

1 College of Business, Zayed University, Abu Dhabi, United Arab Emirates 